\title{
Transcriptomics analysis reveals the effect of Broussonetia papyrifera $L$. fermented feed on meat quality traits in fattening lamb
}

\author{
Xuejiao An ${ }^{1}$, Shengwei Zhang ${ }^{2}$, Taotao Li ${ }^{1}$, Nana Chen ${ }^{1}$, Xia Wang ${ }^{1}$, Baojun Zhang ${ }^{2}$, Youji Ma $^{\text {Corresp. } 1}$ \\ ${ }^{1}$ College of Animal Science and Technology, Gansu Agricultural University, Lanzhou, Gansu, China \\ 2 Gansu Provincial Farmer Education and Training Station, Lanzhou, China \\ Corresponding Author: Youji Ma \\ Email address: yjma@gsau.edu.cn
}

To date, utilization of feed grains is increasing, which competes for human food. It is imperative to develop and utilize unconventional feed materials. Broussonetia papyrifera $L$. (B. papyrifera) is a good feeding material with high crude protein, crude fat, and low crude fiber, which is widely distributed in China. In this study, 12 Dorpero" $\times \mathrm{Hu}$ o crossbred weaned male lambs were seleted into 4 groups based on the feed that ratio of the $B$. papyrifera fermented feed in the total mixed diet $(0 \%, 6 \%, 18 \%$, and $100 \%)$, to character the lambs' longissimus dorsi (LD) fatty acids, morphology and transcriptome. Results showed that the muscle fiber's diameter and area were the smallest in the group $100 \%$. The highest content of beneficial fatty acids and the lowest content of harmful fatty acids in group 18\%. RNA-seq identified 443 differentially expressed genes (DEGs) in the LD of lambs from 4 groups. Among these genes, 169 (38.1\%) were up-regulated and 274 (61.9\%) were down-regulated. The DEGs were mostly enriched in in fatty acid metabolism, arginine and proline metabolism, and PPAR signaling pathways. Our results provide knowledge to understand effect of different ratios of $B$. papyrifera fermented feed on sheep meat quality traits, also a basis for understanding of the molecular regulation mechanism of $B$. papyrifera fermented feed affecting on sheep meat quality. 


\section{Transcriptomics analysis reveals the effect of Broussonetia} papyrifera $L$. fermented feed on meat quality traits in fattening lamb

Xuejiao An ${ }^{1}$, Shengwei Zhang ${ }^{2}$, Taotao Li $^{1}$, Nana Chen ${ }^{1}$, Xia Wang ${ }^{1}$,

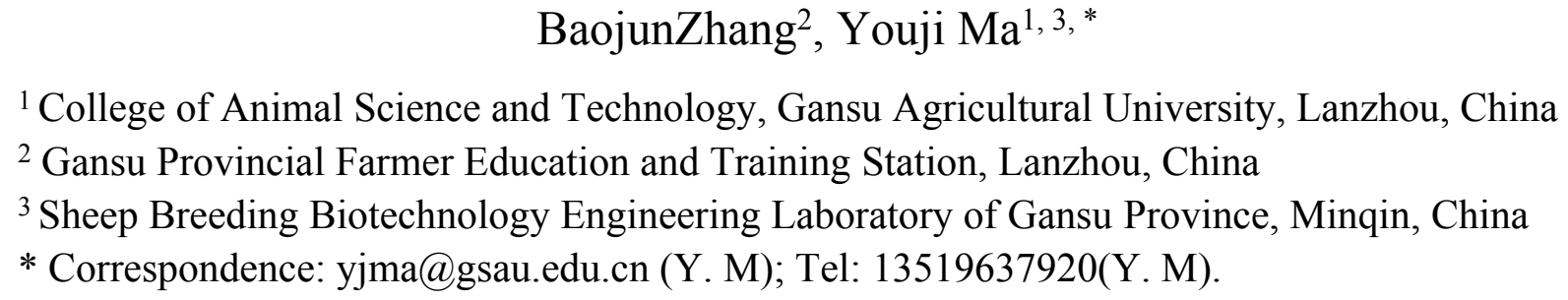

Abstract: To date, utilization of feed grains is increasing, which competes for human food. It is imperative to develop and utilize unconventional feed materials. Broussonetia papyrifera L. (B. papyrifera) is a good feeding material with high crude protein, crude fat, and low crude fiber, which is widely distributed in China. In this study, 12 Dorper $\widehat{ } \times \mathrm{Hu} q$ crossbred weaned male lambs were seleted into 4 groups based on the feed that ratio of the B. papyrifera fermented feed in the total mixed diet $(0 \%, 6 \%, 18 \%$, and $100 \%)$, to character the lambs' longissimus dorsi (LD) fatty acids, morphology and transcriptome. Results showed that the muscle fiber's diameter and area were the smallest in the group $100 \%$. The highest content of beneficial fatty acids and the lowest content of harmful fatty acids in group 18\%. RNA-seq identified 443 differentially expressed genes (DEGs) in the LD of lambs from 4 groups. Among these genes, 169 (38.1\%) were up-regulated and 274 (61.9\%) were down-regulated. The DEGs were mostly enriched in in fatty acid metabolism, arginine and proline metabolism, and PPAR signaling pathways. Our results provide knowledge to understand effect of different ratios of $B$. papyrifera fermented feed on sheep meat quality traits, also a basis for understanding of the molecular regulation mechanism of $B$. papyrifera fermented feed affecting on sheep meat quality.

Key words: B. papyrifera fermented feed; sheep; meat quality; transcriptome

\section{INTRODUCTION}

Broussonetia papyrifera L. (B. papyrifera), is a broad-leaved woody specie with a deciduous, dioecious, and dichogamous plant (Hong et al. 2009). It is native to southern China and Japan, and 
now distributes in China, Malay Peninsula, Japan, and Pacific islands (Zerega et al. 2005; Liu et al. 2009). The plant B. papyrifera has strong stress resistance, can grow normally at arid hillside, valley, and roadside. Studies have been indicated it has multiple function, such as the role of manufacturing paper with it's inner bark (Suleman 1995), its leaves are ideal for feeding animals (Si et al. 2018) and it can also be used in the pharmaceutical industry (Ko et al. 2011). Domestic and foreign scholars have found that B. papyrifera contains a large amount of flavonoids and diphenylpropane compounds, which have certain antioxidant properties. And the mulberry tree contains at least 16 kinds of amino acids, of which 7 are essential amino acids. And its protein content is rich, the total amino acid content is up to $24.35 \%$, it is a good feed material (Wei et al. 2008). It is found that B. papyrifera silage also reduce the ruminal biohydrogenation (Yusuf et al. 2017) and increase the poly-unsaturated fatty acids (PUFA) concentration in the milk (Si et al. 2018).

There are about 300,000 hectares of B. papyrifera in China, widely distributes in basins of Yellow river, Yangtze river, Pearl river and Mingjiang river. B. papyrifera is a kind of nutrientrich woody feed. It contains high crude protein, crude ash, crude fat, phosphorus, and suitable crude fiber content. It has the potential to alleviate the lack of protein feed in China and its dependence on foreign sources. It was reported that the crude protein of B. papyrifera had high degradation rate in the rumen of cows. Therefore, this kind of unconventional woody forage was considered to be of great development value (Wang et al. 2019). Also the B. papyrifera fruits polysaccharides have antioxidant and antibacterial activities (Roth 2016). Many of the plants contain phytochemicals, which had potent antioxidant activities (Lee et al. 1991; Conforti et al. 2008; Xu et al. 2010; Roth 2016). Antioxidant activities have been described for related polyphenolic constituents extracted from the stem, bark and wood of B. papyrifera (Xu et al. 2010). There is report about the radix of B. papyrifera that had the greatest antinociceptive and antiinflammatory effects when different parts of the plant were compared as treatment for chemicalinduced pain and inflammation in rodents (Hong et al. 2013).

With the improvement of people's living standards, consumers' demand for livestock and 
55

poultry products has undergone great changes. People not only demand good taste and flavor, but also demand rich nutrition and benefit human health (Lin et al. 2014). Due to its high protein content, rich nutrient content, and low fat and cholesterol content, mutton has a growing demand for mutton. The main indicators for comprehensively evaluating individual animal meat production performance and meat nutritional value include meat production, meat quality, muscle nutrition and fatty acid content. The important indicators for evaluating meat quality are tenderness, marble pattern, meat color, etc. (Sun et al. 2017). At the same time, the composition and content of fatty acids in muscle are of great significance to meat flavor and human health (Zhang et al. 2019, Guo et al. 2019). Changing in meat quality traits are regulated by related genes. Therefore, functional genes that affect sheep meat quality can be screened through transcriptome sequencing. At the same time, adding different ratios of B. papyrifera fermented feed to sheep diets can affect meat quality related genes the expression changes to affect sheep meat quality traits. Cao (2017) used Dorper $\times$ Small Tail Han Crossbred and Small Tail Han Sheep as research objects to compare and analyze their longissimus dorsi transcriptome sequencing and screened out 16 functional genes that may affect sheep meat quality traits. Hao et al (2016) used RNA-seq and DNA methylation differential gene joint analysis to obtain a large number of genes related to muscle development, muscle meat traits, muscle energy and lipid metabolism, and cellular defense and stress response. In light of this, different ratio of B. papyrifera fermented feed was used as protein feed to feed fattening lambs. Measuring fatty acid content and haematoxylin and eosin (HE) staining to observe the longissimus dorsi (LD) phenotype, to study the feeding effect of $B$. papyrifera fermented feed. Then analyze the transcriptome data, to screen differential genes that relate to B. papyrifera fermented feed. Conjoint analysis explored the influence of B. papyrifera fermented feed on the quality of lamb meat, and screened out the appropriate addition ratio.

\section{MATERIAL AND METHODS}

\section{Overview of experimental program}

This paper mainly explores the molecular regulation mechanism of different ratios of $B$. papyrifera fermented feed on sheep meat quality. We randomly selected 12 crossbred weaned male 
82

lambs divided into 4 groups (3 lambs per group) fed that ratio of the B. papyrifera fermented feed in the total mixed diet $(0 \%, 6 \%, 18 \%$, and $100 \%)$ for 60 days. HE staining and analysis of fatty acid content of LD muscle, a suitable ratio of fermented feed for B. papyrifera was initially selected. Then conduct transcriptomics analysis to screen the key genes that affect meat quality and predict the biological functions of these genes in fatty acid synthesis and metabolism. Finally, combining the phenotypic data and the transcriptome results, explore the effect of B. papyrifera fermented feed on the quality of lamb meat, and select the appropriate addition ratio. (Figure 1).

\section{Chemicals and reagents}

$\mathrm{NaOH}$ (Jinhuitaiya, Tianjin), $\mathrm{CH}_{3} \mathrm{OH}$ (jingke, Wuxi), TRIpure Reagent (DiNing Biotech, China), $\mathrm{CHCl}_{3}$ (Beyotime), $\mathrm{NaCl}$ (jingke, Wu xi), 14\%BF3-CH3OH (Xiya, Shandong), Eosin Staining Solution (Beyotime), Hematoxylin Staining Solution (Beyotime), Evo M-MLV RT Kit with gDNA Clean for qPCR (Accurate Biotechnology (Hunan) Co., Ltd), YBR Green Premix Pro Taq HS qPCR Kit (Accurate Biotechnology (Hunan) Co., Ltd),

\section{Ethics approval}

Experimental animals were reviewed and approved by the Animal Committee of Gansu Agricultural University (GSAU-2019-76).

\section{Preparation of experimental animals}

12 crossbred weaned male lambs Dorper $\widehat{\lambda} \times \mathrm{Hu}$ ㅇ were selected, which with same weight (20 kg/ lamb), similar ages and good health. All fed in Gansu Zhongtian Sheep Industry Co., Ltd. (Longxi China). Randomly divided into 4 groups ( 3 lambs per group) based on the feed that ratio of the B. papyrifera fermented feed in the total mixed diet $(0 \%, 6 \%, 18 \%$, and $100 \%)$. There is transition period of 7 days, a pre-test period of 7 days and a formal period of 60 days. Refer to NRC (2007) standard for $20 \mathrm{~kg}$ lamb with a daily weight gain of $200 \mathrm{~g} / \mathrm{d}$. The diet formula was shown in Table 1. Feed the same amount twice a day at 08:00 and 18:00, respectively, and drink freely.12 lambs were euthanized after 60 days of feeding each lamb was given intravenous injection of $360 \mathrm{mg}$ sodium pentobarbital without heartbeat, continuous non-spontaneous breathing for 2-3 minutes, and no blinking reflex, and then dissected. Collecting the LDs: one 
109

110

111

112

113

114

115

116

117

118

119

120

121

122

123

124

125

126

127

128

129

130

131

132

133

sample was immediately placed in liquid nitrogen and subsequently cryopreserved at $-080^{\circ} \mathrm{C}$ for the extraction of total RNA, the second was placed in an ice box and subsequently cryopreserved at $-20^{\circ} \mathrm{C}$ to extract fatty acids, and the last was fixed with $4 \%$ paraformaldehyde for approximately $48 \mathrm{~h}$, dehydrated in a gradient series of ethanol, cleared inxylene and embedded in paraffin. The tissues were sectioned at $5 \mathrm{~mm}$ thickness and used for HE staining.

\section{Fatty acid analysis}

Frozen samples were thawed $12 \mathrm{~h}$ prior to analyse at $4{ }^{\circ} \mathrm{C}$, and weighed $5 \mathrm{~g}$ LD muscle on an electronic balance. In order to accurately and quickly extract the lipids in the LD, total lipids were extracted with $\mathrm{CHCl}_{3} / \mathrm{CH}_{3} \mathrm{OH}(2: 1, \mathrm{~V} / \mathrm{V})$ as described by Zlatkis et al (1953) with some modifications. Fatty acid methyl esters (FAME) were prepared as following from the methods as described previously (Liu 2015) with some modification. Extracted lipids (approximately $10 \mathrm{mg}$ ) were combined with BHT and $2.0 \mathrm{~mL} \mathrm{NaOH}-\mathrm{MeOH}$ solution $(0.1 \mathrm{~mol} / \mathrm{L})$, saponify at $60{ }^{\circ} \mathrm{C}$ for 60 min. After the solution was clear and transparent, test the tube under $4{ }^{\circ} \mathrm{C}$ running water cool to room temperature; then add $2.0 \mathrm{~mL}$ of $14 \% \mathrm{BF}_{3}-\mathrm{CH}_{3} \mathrm{OH}$ solution, methylate at $60{ }^{\circ} \mathrm{C}$ for 15 min, and cool the test tube to RT under $4{ }^{\circ} \mathrm{C}$ of tap water; add $3 \mathrm{~mL}$ of $\mathrm{n}$-hexane, $1 \mathrm{~mL}$ of $25 \%$ $\mathrm{NaCl}$ solution and $6 \mathrm{~mL}$ of distilled water was shaken vigorously, centrifuged at $6000 \mathrm{r} / \mathrm{min}$ for 10 min, the upper layer of FAME was collected, the lower layer solution was repeatedly extracted once with n-hexane, combined FAME, added an appropriate amount of anhydrous sodium sulfate, and all were sucked out with a disposable needle, and the organic phase was filtered. The membrane is placed at the front of the needle tube for filtration, concentrated to dryness under the protection of nitrogen, the residue is dissolved in n-hexane and fixed to a $2.0 \mathrm{~mL}$ volumetric flask, stored at $-20{ }^{\circ} \mathrm{C}$ for future use, until $\mathrm{GC}$ detection.

Derivatized methyl esters of fatty acids were separated and quantified by gas chromatograph (7820A, Aglilent Technologies, California, USA). The capillary column was a 100 $\mathrm{m} \times 0.25 \mathrm{~mm} \times 0.2 \mu \mathrm{m}(\mathrm{SPTM}-2560$; Sigma Louis, MO, USA). The carrier gas (Nitrogen) flow rate 
134

135

136

137

138

139

140

141

142

143

144

145

146

147

148

149

150

151

152

153

154

155

156

157

158

159

160

was $1.5 \mathrm{~mL} \mathrm{~min} \mathrm{~m}^{-1}$, The flow rate of gas (Hydrogen) was $40 \mathrm{~mL} \cdot \mathrm{min}^{-1}$, The flow rate of air was 400mL.min ${ }^{-1}$. Split injection, split ratio 60:1, injection volume 1.0 $\mu$ L. Injector temperature was set as $260{ }^{\circ} \mathrm{C}$. The initial oven temperature was programmed at $140{ }^{\circ} \mathrm{C}$ and maintained for $5 \mathrm{~min}$, then increased to $200{ }^{\circ} \mathrm{C}$ at $2{ }^{\circ} \mathrm{C} \mathrm{min}-1$, increased to $230{ }^{\circ} \mathrm{C}$ at $6{ }^{\circ} \mathrm{C} / \mathrm{min}$ and keep $20 \mathrm{~min}$.

\section{Haematoxylin and eosin staining}

Section of LD of was stained with H\&E as described previously (Asuka et al. 2017). Then was observed under a microscope, and photographed using ImageView.

\section{Muscle fiber measurement}

The HE-stained section was photographed under the $20 \times$ and $40 \times$ microscope using the ImageView microphase system, and the diameter and area of the muscle fibers under the $40 \times$ microscope were determined using ImageJ software.

\section{Total RNA extraction, cDNA library preparation}

Total RNA was extracted from each sample using TRIpure Reagent according to instructions. The concentrations and quality of RNA samples were examined by NanoDrop2000 (Thermo)and Agilent 2100 (Agient). The total RNA of the aforementioned samples was used to construct an RNA-Seq library, which were sequenced in parallel on Illumina HiSeq 2000 system by Biomarker technologies (Beijing, China).

\section{Identification and quantification of DEGs}

Identification of differential genes used FPKM (fragments per kilobase per million reads) (Mortazavi et al. 2008). Differential expression analyses of genes among four groups were implemented using the Cuffdiff (Trapenll et al. 2013). Genes with indexes fold change (FC) $>1.5$ and FDR $<0.05$ were considered as DEGs.

\section{Functional annotation and pathway analysis of DEGs}

The functional of DEGs were identified through GO and KEGG database. GO annotation and KEGG pathways analyses by the GOseq R package and KOBAS software, the $p$ value $\leq 0.05$ were defined as significant enriched by DEGs.

\section{Validation of RNA-seq results}


To verify reliability of the transcriptomic profiling data, quantitative real-time PCR (qRTPCR) was performed for 9 randomly selected DEGs (FABP3, ECI1, ACADVL, GOT1, LPIN1, MLYCD, PLIN5, RASD1 and SELENOW). GAPDH was used as a reference gene in quantitative analysis. Using Evo $M-M L V$ RT Kit with gDNA Clean for qPCR to reverse transcribe RNA into cDNA, and using SYBR Green Premix Pro Taq HS qPCR Kit and run on the Roche LightCycler96. The relative expression was calculated using the $2^{-\Delta \Delta \mathrm{Ct}}$ method (Vanslyke 2000). The qRT-PCR primers are listed in the electronic supplementary material, table S1.

\section{Statistical analysis}

All statistical analyses were conducted with SPSS 22.0 software (SPSS Inc., Chicago, IL, USA), the least significant difference (LSD with Fischer's) method in one-way analysis of variance (ANOVA). The results were expressed as mean \pm standard error. $P$ value $<0.05$ were considered as statistically significant.

\section{RESULTS}

\section{Comparison of differences in fatty acid composition and content among different groups}

\section{Analysis of saturated fatty acid content}

A total of 11 kinds of saturated fatty acids were detected in LD of lamb with different $B$. papyrifera fermented feed, including 4 odd saturated fatty acids and 7 even saturated fatty acids. Among the even saturated fatty acids, butyric acid (C4:0), capric acid (C10:0) palmitic acid (C6:0) and stearic acid (C18:0)were not significantly different among the four groups $(P>0.05)$. The content of lauric acid(C12:0), myristic acid (C14:0) and arachidic acid (C20:0) in the 100\% group was significantly higher than the other three groups $(P<0.05)$. Among the odd saturated fatty acids, tridecanoic acid (C13:0) and tricosanoic acid (C23:0) were not significantly different among the four groups $(P>0.05)$. The content of pentadecanoic acid $(\mathrm{C} 15: 0)$ and heptadecanoic acid (C17:0) group 100\% was significantly higher than other groups (Table 2 and S2).

\section{Analysis of unsaturated fatty acid content}

A total of 15 kinds of unsaturated fatty acids were detected in LD of lamb fed with different B. papyrifera fermented feed, including 7 kinds of MUFA and 8 kinds of PUFA. Among the 
monounsaturated fatty acids, there are three insignificant differences between the four groups, namely myristic acid (C14:1), palmitoleic acid (C16:1), nervonic acid (C24: 1) and trans linoleic acid $(\mathrm{C} 18: 2 \mathrm{n} 6 \mathrm{t})(P>0.05)$. Among the unsaturated fatty acids, the content of Cis-10-pentadecenoic acid (C15:1) and cis-10-heptadecenoic acid (C17:1) and were gradually increased with the addition of B. papyrifera fermented feed. Among the polyunsaturated fatty acids, the content of four fatty acids also increased with the addition of mulberry fermented feed, including linoleic acid (C18:2n6c), $\gamma$-linolenic acid (C18:3n6), alpha-linolenic acid (C18:3n3), cis-8, 11,14-eicosatrienoic acid (C20:3n6) and DHA (C22:6n3) (Table 3 and S2).

\section{Analysis of total fatty acid content}

The functional fatty acids that are closely related to human health mainly n3 and n6 PUFAs. This study found that n6 was not significantly different between the four groups $(P>0.05)$, but its content increased with the amount of addition, the content of $\mathrm{n} 3$ in the group $100 \%$ was significantly higher than other groups $(P<0.05)$. Both n6/n3 and $\mathrm{P} / \mathrm{S}$ can be used to measure the nutritional value of meat. In this study, P/S was the highest in the $100 \%$ group, while n6/n3 was the highest in the group 18\% (Table 4 and S2).

\section{Comparison of morphological differences of $L D$ in different groups}

HE staining of the LD of lamb in different groups, the cross-section staining results showed that the muscle fibers were polygonal, all arranged tightly, the muscle bundle gap was large, and the intramuscular membrane was obvious (Figure 1A-D). The longitudinal section shows that the muscle fibers are long fusiform, and the nuclei are blue elliptical or rod-shaped (Figure 2E-H). From Figure 1I-J and TableS3, the difference between the three groups of muscle fiber's area and diameter $0 \%, 18 \%$ and $100 \%$ was significant $(P<0.05)$, while the difference between $6 \%$ and 18 was not significant $(P>0.05)$, but $18 \%$ was less than $6 \%$, indicating that with the increased in the amount of $B$. papyrifera fermented feed the muscle fiber's area and diameter was decreased.

\section{Data analysis from RNA-seq}

In view of the influence of different proportions of $B$. papyrifera fermented feed on the meat quality of fattening lamb, transcription level changes in the LD were analyzed using the Illumina 
215 HiSeq 2000 platform, and prepared to construct cDNA libraries for RNA-seq. As shown in table

2165 , After filtering, the clean data of each sample reached 6.07 GB, the percentage of Q30 bases was

217 greater than $93.57 \%$. The percentage of clean reads that mapped into the sheep reference genome

218 ranged from 96.79 to $97.57 \%$. About $80 \%$ of clean reads were uniquely mapped and used for

219 subsequent analysis.

220 Gene expression analysis

221 Comparing the three groups to yield a total of 443 DEGs, among them, 48 (19 up-regulated

222

223

224

225

226

227

228

229

230

231

232

233

234

235

236

237

238

239

240

241

and 29 down-regulated), 104 (38 up-regulated and 66 down-regulated) and 198 (84 up-regulated and 141 down-regulated) DEGs belonged to $6 \%, 18 \%$ and $100 \%$, respectively. The 6 DEGs (2 upregulated and 4 down-regulated) were commonly regulated by effecting of fermented feed from B. papyrifera in the three groups (Figure 3A). A total of 89, 157 and 269 DEGs were identified in the groups of $0 \%$ vs6 \%,0 \% vs18\%, and $0 \%$ vs100\%, respectively $(\mathrm{FC}>1.5, \mathrm{FDR}<0.05)$. After adding 6\%, the number of down-regulated DEGs (52) were more than the number of upregulated DEGs (37). When fed all B. papyrifera fermented feed, the number of up-regulated DEGs increased from $37(6 \%)$ to $98(100 \%)$, and the down-regulated DEGs increased from 52 $(6 \%)$ to $171(100 \%)$ (Figure 3B). Hierarchical clustering represents the difference and similarity of 443 DEGs (Figure 3C and Table S4). The results showed that there was a significant difference in gene expression profiles differences among the four groups. With the increase of the added amount, the genes with high expression at $0 \%$ were gradually down-regulated, while those with low FPKM at $0 \%$ were gradually up-regulated. It indicated that the addition of $B$. papyrifera fermented feed a set of gene expression or induces another set of gene expression, although these changes were to regulate the meat quality performance.

\section{Expression pattern and functional analysis of the DEGs in LD of sheep}

According to the expression profiles, 443 DEGs were classified into 8 clusters by coexpression clustering (Figure 4 and Table S5). A total of 16 and 67 genes were classified as clusters 4 and 6 , which were rapidly down-regulated within $0 \%$ to $18 \%$ and then gradually up-regulated within $100 \%$. Most of them participated in pathways such as "Rap1 signaling pathway", and 
242 "protein digestion and absorption", it indicates that those genes were transiently inhibited by $B$. 243 fermenta. While the genes in clusters 1 and 5 were up-regulated from $0 \%$ to $18 \%$, and gradually 244 down-regulated within 100\%. This result indicates that those genes were transiently promoted by 245 B. fermenta. Most of them participated in pathways such as "glucagon signaling pathway", "PPAR 246 signaling pathway" and "fat digestion and absorption". The genes belonging to clusters 2, 7 and 8 were continuously down-regulated. Transcription is inhibited by B. fermented feed, most of which are rich in " MAPK signaling pathway" and " cAMP signaling pathway" pathways. Cluster 3 contains fewer genes (31), and the expression levels of these genes are significantly up-regulated with the addition of fermented feed from B. papyrifera, most of which are rich in the "AMPK signaling pathway" and "Circadian rhythm" pathways.

252

253

254

255

256

257

258

259

260

261

262

263

264

\section{GO classification analyses}

Annotated genes were divided into three major functional categories: biological processes (BP), cellular components (CC) and molecular functions(MF). It is obvious that there were more functional terms for BP and relatively few transcripts for $\mathrm{CC}$ and $\mathrm{MF}$. Compared with downregulated transcripts, detoxification (GO: 0098754), synapse (0045202), synapse part (0044456) antioxidant activity (GO:0016209) terms were peculiar in up-regulated DEGs; nucleoid (0009295) was unique in upregulation GO terms (Figure 5A, B and Table S6).

\section{KEGG annotation analyses}

KEGG pathway analysis was conducted to investigate whether the genes in LD of the sheep participate in some special pathways with the addition of different $B$. fermenta. fermented feed. Top20 of KEGG enrichment showed that up-regulated DEGs were highlighted in "fatty acid degradation (ko00071)", "circadian rhythm(ko04710)", "tryptophan metabolism (ko00380)", "arginine and proline metabolism (ko00330)", "regulation of lipolysis in adipocytes(ko04923)", “glycerolipid metabolism (ko00561)” and “cGMP-PKG signaling pathway(ko04022)”. Moreover, "pertussis (ko05133)", "proteoglycans in cancer (ko05205)", "complement and coagulation cascades (ko04610)", "ECM-receptor interaction(ko04512)", "pathways in cancer (ko05200)"and "Rap1 signaling pathway(ko04015)" annotated the most down-regulated DEGs (Figure 5A, B, and 
269

270

271

272

273

274

275

276

277

278

279

280

281

282

283

284

285

286

287

Table S7).

RNA-Seq expression validation by qRT-PCR

As shown in figure 7 and S8, we selected 9 DEGs that were closely associated with the meat quality. The result showed that qRT-PCR expression patterns were consistent with the changing trends from RNA-seq data.

PPI network

The PPI network of DEGs related to meat quality in the LD muscle of lamb were presented in figure 8 . There were 43 edges and 17 nodes in the network. Based on the PPI natwork, ACSL1 (degree=9), $A C A D V L$ (degree=9), ECI1 (degree=9), ECHS1 (degree=9) were the top four hub genes.

\section{Discussion}

\section{Effect of $B$. papyrifera fermented feed on meat quality traits}

The internal quality of meat is dependent on certain characteristics of muscle fibers. Besides, there are many factors that affect the differences of muscle fibers, such as growth and development stage, gender, environment, and nutrition. The size and number of muscle fibers are important factors that affect meat quality. Therefore, the characteristics of muscle fibers are of great significance to the meat quality characteristics and growth of animals (Shen et al. 2014; Kim et al. 2018). Muscle bundles were composed of muscle fibers, and the size of muscle fiber's diameter is also related to the shearing force. The smaller the muscle fiber's diameter, the tenderer the meat quality. At the same time, the cross-sectional area of the muscle fiber was also one of the important indicators for judging the quality of the meat (Bidanel et al. 1991).In this study, the diameter and area of muscle fibers decreased with the increase of the ratio of $B$. papyrifera fermented feed (Refer to Fig 2), indicating that the addition of B. papyrifera fermented feed was directly proportional to muscle tenderness. Therefore, this feed can be added as a protein feed in ruminant diets for improving muscle tenderness.

Lauric acid (12:0), myristic acid (14:0) and palmitic acid (16:0) in long-chain SFA are closely related to cholesterol and can harden human blood vessels, which was the reason to cause 
296

297

298

299

300

301

302

303

304

305

306

307

308

309

310

311

312

313

314

315

316

317

318

319

320

321

322

cardiovascular disease and arteriosclerosis, there are some epidemiology showing that stearic acid (C18:0) is related to coronary heart disease (Hu et al. 1999; Hunter et al. 2010). In this study, the content of lauric acid (12:0) and myristic acid (14:0) in the group100\% was higher than other groups (Refer to Table 2), indicating that excessive addition of B. papyrifera fermented feed in the ruminant feed would cause long chains SFA increase. The intake of unsaturated fats can effectively reduce the level of cholesterol in the body and prevent atherosclerosis (Cameron et al. 2000; Wood et al. 2008). PUFA have been proven to prevent and treat cardiovascular diseases, and also have important physiological effects such as delaying aging and anti-cancer. MUFA plays an important role in lowering cholesterol (Harris et al. 2007). The $n 3$ series of PUFA play a variety of functions in the human body. They can reduce triglycerides in blood lipids, improve blood vessels and eliminate inflammation, and reduce the morbidity and mortality of cardiovascular disease patients (Philip et al. 2013). In the present study, PUFA were higher in other three groups than that in control group, and it might due to the antimicrobial activities in the diet supplemented with $B$. papyrifera fermented feed (Refer to Table 4), as it is reported that prenylated flavonoids isolated from B. papyrifera have antimicrobial activity (Sohn et al. 2004; Sohn et al. 2010). which affects the biohydrogenation of unsaturated fatty acids by ruminant rumen microorganisms, and also dietary antioxidant activity might increase PUFA content in meat (Sanchez et al. 2012; Belles et al. 2019). Combining the content of beneficial fatty acids such as DHA(C22:6n3), linoleic $\operatorname{acid}(\mathrm{C} 18: 2 \mathrm{n} 6 \mathrm{c})$ and $\alpha$-linolenic acid(C18:3n3) and harmful fatty acids such as lauric acid(C12:0), myristic acid(C14:0) and stearic acid(C18:0) in the 4 groups, it showed that the $18 \%$ group has a higher content of beneficial fatty acids and a lower count of harmful fatty acid, which would be more beneficial for the consumer's health.

\section{Effects of B. papyrifera fermented feed on meat quality-related DEGs and fatty acid} metabolic pathways

In this study, we screened 443 genes whose mRNA abundance changes not less than 1.5 times based on FDR (Refer to Fig 3). Intramuscular fat is one of the indicators reflecting meat quality and flavor, and is closely related to carcass and meat quality. B. papyrifera fermented feed mainly 
323

324

325

326

327

328

329

330

331

332

333

334

335

336

337

338

339

340

341

342

343

344

345

346

347

348

349

improves the intramuscular fat content of fattening lamb through nutritional regulation, thereby affecting meat quality performance. By analyzing the KEGG pathway of differentially expressed genes, it can be seen that 4 DEGs (ACSL1, AQP7, FABP3 and PLIN5) are enriched in the PPAR signaling pathway (Refer to Fig 8). FABP3 mainly regulates the body's fat and glucose balance in the PPAR signaling pathway, and plays an important role in the transportation and metabolism of fatty acids in cells. It can transport long-chain fatty acids from the cell membrane to fatty acid oxidation, triglyceride and phospholipid synthesis (Veekamp 1995). FABP3 gene mutations and mRNA expression levels have a significant impact on intramuscular fat, which in turn affects muscle tenderness (Wang et al. 2015). ACSL1 is the most important synthetase for acyl-CoA to synthesize triglycerides, which helps fatty acid transport and triglyceride deposition (Richards et al. 2006). $A Q P 7$, a water/glycerol transporting protein, regulates adipocyte glycerol efflux and influences lipid and glucose homeostasis (Oikonomou et al. 2020). PLIN5 is expressed on both lipid droplets and mitochondria, and may participate in the interaction between lipid droplets and mitochondria (Wang et al. 2013). Muscle-specific overexpression of PLIN5 increases the storage of lipid droplets in muscle cells and also increases the rate of oxidative gene expression and metabolism (Harris et al. 2015). The formation of larger lipid droplets with a higher degree of esterification, increased methylene content and more saturated lipids (Nils et al. 2015). The above results indicate that these four genes mainly promote the deposition of intramuscular fat by participating in the synthesis of triglycerides and polyunsaturated fatty acids, thereby changing muscle tenderness. In this study, the expression of ACSL1, AQP7, FABP3 and PLIN5 genes increased with the addition of $B$. papyrifera fermented feed, and the expression of all genes decreased in $100 \%$ group (Refer to Fig 7), indicating that $18 \%$ amount of added B. papyrifera fermented feed can improve meat quality.

By analyzing the KEGG pathway of differentially expressed genes, it could be seen that there were four genes (ECHS1, ACSL1, ACADVL and ECI1) that were significantly enriched in the fatty acid metabolism signaling pathway (Refer to Fig 8). ECHS1 in cells could activate mammalian target proteins, and animal target proteins may enhance LPL expression through the PPAR 
350

351

352

353

354

355

356

357

358

359

360

361

362

363

364

365

366

367

368

369

370

371

372

373

374

375

376

pathway. LPL was involved in the metabolism and transport of lipids, and mainly hydrolyzes the chylomicrons and very low-density lipoproteins present on the surface of capillary endothelial cells to produce fatty acids ( $L i$ et al. 2014). ACADVL mainly catalyzes the oxidation of fatty acids to form C 2-C 3 double bonds, and usually catalyzes C 16-acetyl COA or even longer chain fatty acids (Aoyama et al. 1995). The long-chain fatty acyl COA is transported to the mitochondria, firstly binds to $V L C A D$, and interacts with the mitochondrial trifunctional protein. After 2-3 cycles of oxidation, the medium-chain fatty acyl CoA is formed (Houten 2010). The protein encoded by ECI1 was an important mitochondrial enzyme involved in the $\beta$ oxidation of unsaturated fatty acids, which was mainly involved in the metabolic process of fatty acids (Williams 1991). In this study, the expression level of ECII increased with the addition of B. papyrifera fermented feed, reaching the highest in the $18 \%$ group, but decreased in the $100 \%$ group. The expression level of $A C A V D L$ and ECHS1 rose to the highest after $6 \%$ B. papyrifera fermented feed, and then decreased with the increase of the added amount (Refer to Fig 7). It showed that adding the appropriate amount of B. papyrifera fermented feed would increase the synthesis of long-chain fatty acids, while excessive addition of $B$. papyrifera fermented feed would increase fatty acid metabolism and reduce fatty acid content in the body, thereby affecting the fat deposition on meat quality in the LD of lamb.

\section{Conclusion}

Although there are many researches on B. papyrifera in animal breeding, they have focused on its antioxidant activity, rumen hydrogenation and its effect on fatty acids. There is no report on the specific influence mechanism of $B$. papyrifera fermented feed on the meat quality traits of animal. To our best knowledge, this is the first report about the effect of adding different $B$. papyrifera fermented feed on the meat quality traits and changes of the longissimus dorsal transcriptome of fattening lamb. First, the fatty acid content and muscle fiber morphology of the longissimus dorsal were studied. It was found that after adding B. papyrifera fermented feed, the muscle fiber's diameter of the muscle became smaller, the tenderness became more tender, and the content of polyunsaturated fatty acid was the highest in the group $18 \%$. Finally, a total of 443 
377

378

379

380

381

382

383

384

385

386

387

388

389

390

391

392

393

394

395

396

397

398

399

400

401

402

403

404

405

DEGs were identified in the four groups. We screened some DEGs that related to synthesis of fatty acids, most of which were up-regulated in the groups $6 \%$ and $18 \%$, and down-regulated in the group $100 \%$. Our results show that proper addition of Pichia fermented feed can help the synthesis of long-chain unsaturated fatty acids and the deposition of intramuscular fat. Therefore, it is recommended to add $18 \%$ B. papyrifera fermented feed to lamb feed to improve meat quality traits.

Data availability statement: The sheep mRNA sequences in our manuscript have been deposited in the SRA of the NCBI, accession number and link are PRJNA660919 and https://www.ncbi.nlm.nih.gov/Traces/study/?acc=PRJNA660919,

Biosample accession SAMN15963870-15963881.

Supplementary Materials: TableS1: Gene information used for primer design, Table S2: Fatty acid determination results, Table S3: Muscle fiber's diameter and area, Table S4: List of all DEGs, Table S5: The co-expression analysis of DEGs, Table S6: List of GO analysis result, Table S7: List of KEGG analysis result, Table S8: The results of qRT-PCR.

Author Contributions: Conceptualization, Methodology, Software, Formal analysis, Writing original draft, X A; Methodology S Z; Methodology, Software, Formal analysis, T L; Formal analysis, N C; Methodology, Software, X W; Methodology, B Z; Conceptualization, Writing review \& editing, Supervision, Project administration, Funding acquisition, Y M. All authors have read and agreed to the published version of the manuscript.

Funding: It was supported by the National Key R\&D Program of China (2018YFD0502100).

Acknowledgments: Thanks to Zhongtian Sheep Industry Co., Ltd. for providing us with the lamb breeding base, and BMK Cloud (www.biocloud.net) for supporting in data analysis of this study.

Conflicts of Interest: All authors declare no conflicts of interest.

\section{REFERENCES}

Aoyama T, Souri M, Ushikubo S, Kamijo T, Hashimoto. 1995. Purification of human very-long-chain acylcoenzyme A dehydrogenase and characterization of its deficiency in seven patients. Journal of Clinical Investigation 95(6): 2465-2473. DOI 10.1172/JCI117947

Asuka H, Tomoyuki A, Atsushi H, Kazuhiro S, Hiromichi A, Borjigin S, Mio Y, Akane S, Atchalalt K, Kazuko O, Rika F,Shoei S, Yoshikazu N. 2017. Histochemical properties of bovine and ovine mammary 
406

407

408

409

410

411

412

413

414

415

416

417

418

419

420

421

422

423

glands during fetal development. Journal of Veterinary Medical Science 80(2): 263-271. DOI 10.1292/jvms.17-0584

Marc B, Pedro R, José AB. 2018. Supranutritional doses of vitamin E to improve lamb meat quality. Meat Science 149: 14-23. DOI 10.1016/j.meatsci.2018.11.002

Bidanel JP, Bonneau M, Pointillart A, Gruand J, Mourot J, Demade I. 1991. Effects of exogenous porcine somatotropin (pST) administration on growth performance, carcass traits, and pork meat quality of Meishan, Pietrain, and crossbred gilts. Journal of Animal Ence 69(9): 3511. DOI $10.1080 / 00071669108417414$

Cameron ND, Enser M, Nute GR, Whittington FM, Penman JC; Fisken AC, Perry AM, Wood JD. 2000. Genotype with nutrition interaction on fatty acid composition of intramuscular fat and the relationship with flavour of pig meat. Meat Science 55(2):187-195. DOI 10.1016/S0309-1740(99)00142-4

Cao Y. 2017 Comparative Analysis on Genome-wide Methylation and RNA-seq in Longissimus Dorsi Muscle between Dorper $\times$ Small Tail Han Crossbred and Small Tail Han Sheep. DOI: 10.27228/d.cnki.gnmmu.2020.000086

Conforti F, Sosa S, Marrelli M, Menichini F, Statti G A, Uzunov D, Tubaro A, Menichini F, Della R, Loggia.2008. In vivo anti-inflammatory and in vitro antioxidant activities of Mediterranean dietary plants. Journal of Ethnopharmacology 116(1): 144-151. DOI 10.1016/j.jep.2007.11.015

Guo JQ, Xu XF, Xie ZK, Yang G. 2019. Research progress on the effect of fatty acids on lamb quality. China Feed, (23). DOI: 10.15906/j.cnki.cn11-2975/s.20192317

Hao Y, Cui Y, Gu X. 2016. Genome-wide DNA methylation profiles changes associated with constant heat stress in pigs as measured by bisulfite sequencing. Sci Rep 6(1):27507. DOI: 10.1038/srep27507

Harris-Ann LSH, Skinner JR, Shew TM, Pietka TA, Abumrad NA, Wolins NE.2015. Perilipin 5-Driven Lipid Droplet Accumulation in Skeletal Muscle Stimulates the Expression of Fibroblast Growth Factor 21. Diabetes 64(8): 2757-2768. DOI 10.2337/db14-1035

Harris WS, Poston WC, Haddock C K. 2007. Tissue n-3 and n-6 fatty acids and risk for coronary heart disease events. Atherosclerosis. DOI 10.1016/j.atherosclerosis.2007.03.018

Hong L, Yang W, Liao Y. 2009. Structure of Flowers and Pollination Mechanism of Broussonetia papyrifera. Journal of South-Central University for Nationalities (Natural Science Edition)

Hong SH, Kwon JT, Shin JY, Kim JE, Cho MH. 2013. Therapeutic Effect of Broussonetia papyrifera and Lonicera japonica in Ovalbumin-induced Murine Asthma Model. Natural Product Communications 8(11): 1609-1614

Houten SM, Wanders RJA. 2010. A general introduction to the biochemistry of mitochondrial fatty acid $\beta$ oxidation. Journal of Inherited Metabolic Disease 33(5): 469-477. DOI 10.1007/s10545-010-9061-2

Hu F B, Stampfer MJ, Manson JoAnn E, Alberto A, Colditz GA, Speizer FE, Hennekens CH, Willett WC. 1999. Dietary saturated fats and their food sources in relation to the risk of coronary heart disease in women. The American journal of clinical nutrition 70(6): 1001-1008. DOI 10.1556/AAlim.28.1999.4.7

Hunter JE, Zhang J, Kris-Etherton PM. 2010. Cardiovascular disease risk of dietary stearic acid compared with trans, other saturated, and unsaturated fatty acids: a systematic review. The American journal of clinical nutrition 91(1): 46-63. DOI 10.3945/ajcn.2009.27661

Kim YM, Choi TJ, Cho KH, Cho ES, Lee JJ, Chung HJ, Baek SY, Jeong Y D. 2018. Effects of sex and breed on meat quality and sensory properties in three-way crossbred pigs sired by Duroc or by a synthetic 
breed based on a Korean native breed. Korean journal for food science of animal resources 38(3): 544. DOI 10.5851/kosfa.2018.38.3.544

Ko HJ, Jin JH, Kwon OS, Kim JT, Son KH, Kim HP. 2011. Inhibition of Experimental Lung Inflammation and Bronchitis by Phytoformula Containing Broussonetia papyrifera and Lonicera japonica. Biomolecules \& Therapeutics 19(3): 324-330. DOI 10.4062/biomolther.2011.19.3.324

Lee SH, Yu JH, Jeong CL, Yoon YC, Back YJ. 1991. The influence of mastitis on the quality of raw milk and cheese. Korean Journal of Dairy Science 39(39): 750-760. DOI 10.1044/jshr.3904.750

Li Y, He PP, Zhang DW, Zheng XL, Cayabyab FS, Yin WD, Tang CK. 2014. Lipoprotein lipase: From gene to atherosclerosis. Atherosclerosis 237(2): 597-608. DOI 10.1016/j.atherosclerosis.2014.10.016

Lin CJ, Jiang JF, Song XM, Wu JL, Shi FX, Jiang YQ. 2014. Comparison of fatty acid composition of F1 generation of Hu sheep and Dorper $\times$ Hu sheep. Animal Husbandry and Veterinary Medicine (04): 58-61. DOI cnki:sun:xmysLiu C Y. 2015. Analysis of functional lipids in tissues of different bovine species and the effect of heat treatment on lipid oxidation. Huazhong Agricultural University. DOI 10.7666/d.Y2803488

Liu ZY, Fan WH, Shen SH. 2009. SRAP Marker in Broussonetia papyrifera. Scientia Silvae Sinicae 45(12): 54-58

Mortazavi A, Williams BA, McCue K, Schaeffer L, Wold B. 2008. Mapping and quantifying mammalian transcriptomes by RNA-Seq. Nature methods 5(7): 621-628. DOI 10.1038/nmeth.1226

Nils B, Madeleen B, William R, Frederik F, Gerrit B, Patrick S, Sander K, Mischa B, Hesselink MKC, Parekh SH. 2015. Perilipin 5 mediated lipid droplet remodelling revealed by coherent Raman imaging. Integrative Biology Quantitative Biosciences from Nano to Macro. DOI 10.1039/c4ib00271g

Oikonomou E, Kostopoulou E, Rojas-Gil AP, Georgiou G, Spiliotis BE. 2020. The metabolic implications of aquaporin 7 (AQP7) promoter variants in lean children and children with obesity. Hormones (Athens, Greece) 19(2): 1-9. DOI 10.1007/s42000-020-00184-z

Philip C, Calder. 2013. Omega-3 polyunsaturated fatty acids and inflammatory processes: nutrition or pharmacology? British Journal of Clinical Pharmacology 75(3):645-662. DOI 10.1111/j.13652125.2012.04374. x

Richards MR, Harp JD, Ory DS, Schaffer JE. 2006. Fatty acid transport protein 1 and long-chain acyl coenzyme A synthetase 1 interact in adipocytes. Journal of Lipid Research 47(3): 665. DOI 10.1194/jlr.M500514-JLR200

Roth Z, Wolfenson D. 2016. Comparing the effects of heat stress and mastitis on ovarian function in lactating cows: basic and applied aspects. Domestic Animal Endocrinology 56: S218-S227. DOI 10.1016/j.domaniend.2016.02.013

Sanchez-Muniz FJ, Olivero-David R, Triki M, Salcedo L, Gonzalez-Munoz MJ, Cofrades S, Ruiz-Capillas C, Jimenez-Colmenero F, Benedi J. 2012. Antioxidant activity of Hypericum perforatum L. extract in enriched n-3 PUFA pork meat systems during chilled storage. Food Research International 48(2): 909-915. DOI 10.1016/j.foodres.2012.07.002 
Shen LY, Luo J, Lei HG, Jiang YZ, Zhu L. 2014. Effects of muscle fiber type on glycolytic potential and meat quality traits in different Tibetan pig muscles and their association with glycolysis-related gene expression. Genetics \& Molecular Research Gmr 14(4): 14366. DOI 10.4238/2015.November.13.22

Si B, Tao H, Zhang X, Guo J, Diao QY. 2018. Effect of Broussonetia papyrifera L. (paper mulberry) silage on dry matter intake, milk composition, antioxidant capacity and milk fatty acid profile in dairy cows. Asian Australasian Journal of Animal Sciences 31(8):1259-1266. DOI 10.5713/ajas.17.0847

Sohn HY, Kwon CS, Son K H. 2010. Fungicidal Effect of Prenylated Flavonol, Papyriflavonol A, Isolated from Broussonetia papyrifera (L.) Vent. Against Candida albicans. J Microbiol Biotechnol 20(10): 1397-1402. DOI 10.4014/jmb.1007.07026

Sohn HY, Son KH, Kwon CS, Kwon GS, Kang SS, 2004. Antimicrobial and cytotoxic activity of 18 prenylated flavonoids isolated from medicinal plants: Morus alba L., Morus mongolica Schneider, Broussnetia papyrifera (L.) Vent, Sophora flavescens Ait and Echinosophora koreensis Nakai. Phytomedicine 11(7-8): 666-672. DOI 10.1016/j.phymed.2003.09.005

Suleman KM. 1995. Suitability of home grown paper mulberry (Broussonetia papyrifera) for pulp and paper manufacture. Pakistan journal of forestry 45(4): 158-162

Sun LM. 2017. Merino sheep and small tail Han sheep meat performance and muscle tissue mRNA-miRNA expression profile integrated analysis. Jilin Agricultural University.

Trapnell C, Hendrickson DG, Sauvageau M, Goff L, Rinn JL, Pachter L. 2013. Differential analysis of gene regulation at transcript resolution with RNA-seq. Nature biotechnology 31(1): 46-53. DOI $10.1038 /$ nbt. 2450

VanSlyke JK, Musil LS. 2000. Analysis of connexin intracellular transport and assembly. Methods 20(2): 156164. DOI 10.1006/meth.1999.0933

Veerkamp JH, Maatman RGHJ. 1995. Cytoplasmic fatty acid-binding proteins: their structure and genes. Progress in Lipid Research 34(1): 17-52. DOI 10.1016/0163-7827(94)00005-7

Wang H, Sreenevasan U, Hu H, Saladino A, Sztalryd C. 2013. Perilipin 5, a lipid droplet-associated protein, provides physical and metabolic linkage to mitochondria. Journal of Lipid Research 54(12): 3539-3539. DOI 10.1194/j1r.M017939ERR

Wang L, Li L, Jiang J, Wang Y, Zhong T, Chen Y, Wang Y, Zhang HP. 2015. Molecular characterization and different expression patterns of the FABP gene family during goat skeletal muscle development. Molecular Biology Reports 42(1): 201-207. DOI 10.1007/s11033-014-3759-4

Wang X, Tang C, Lin Y, Ni K, Yang X. 2019. Assessing nutritive value and in vitro ruminal dry matter digestibility of paper mulberry (Broussonetia papyrifera L.) at the different cutting heights. IOP Conference Series Earth and Environmental Science 387: 012015. DOI 10.1088/1755-1315/387/1/012015

Wei HQ, Liu ZH, Wan W, 2008. General situation and prospect of research on broussonetia papyrifera. Fujian Forestry Science and Technology, 35(4): 261-266. DOI 10.3969/j.issn.1002-7351

Williams T,. Tjian R. 1991. Analysis of the DNA-binding and activation properties of the human transcription factor AP-2. Genes \& Development 5(4): 670-682. DOI 10.1101/gad.5.4.670

Wood JD, Enser M, Fisher AV, Nute GR,Sheard PR, Richardson RI, Hughes SI, Whittington FM. 2008. Fat deposition, fatty acid composition and meat quality: A review. Meat Science 78(4): 343-358. DOI 10.1016/j.meatsci.2007.07.019 
524

525

526

527

528

529

530

531

532

533

534

535

536

537

538

539

540
Xu ML, Wang L, Hu JH, Lee SK, Wang MH, 2010. Antioxidant Activities and Related Polyphenolic Constituents of the Methanol Extract Fractions from Broussonetia papyrifera Stem Bark and Wood. Food Science \& Biotechnology 19(3): 677-682. DOI 10.1007/s10068-010-0095-x

Yusuf AL, Adeyemi KD, Samsudin AA, Goh YM, Alimon AR, Sazili AQ. 2017. Effects of dietary supplementation of leaves and whole plant of Andrographis paniculata on rumen fermentation, fatty acid composition and microbiota in goats. Bmc Veterinary Research 13(1): 349. DOI 10.1186/s12917-0171223-0

Zerega NJ, Clement WL, Datwyler SL, Weiblen GD, 2005. Biogeography and divergence times in the mulberry family (Moraceae). Molecular phylogenetics and evolution 37(2): 402-416. DOI 10.1016/j.ympev.2005.07.004

Zhang DM, Rong H, Liu LX, Li QH, Ge CR, Jia JQ, Xu ZQ, Gu DH,Duan XH. 2019. Study on the difference of muscle nutrition composition and FAS gene expression between Nixi and Aiweiyin chickens. Heilongjiang Animal Science and Veterinary Medicine 583(19):62-65. DOI : cnki:sun:hljx.0.2019-19-013

Zlatkis A, Zak B, Boyle G. 1953. A simple method for isolation and purification of total lipids from animal tissue. Journal of Biological Chemistry 226: 497-509 
Figure 1

Figure 1. Experimental design and procedures

no 


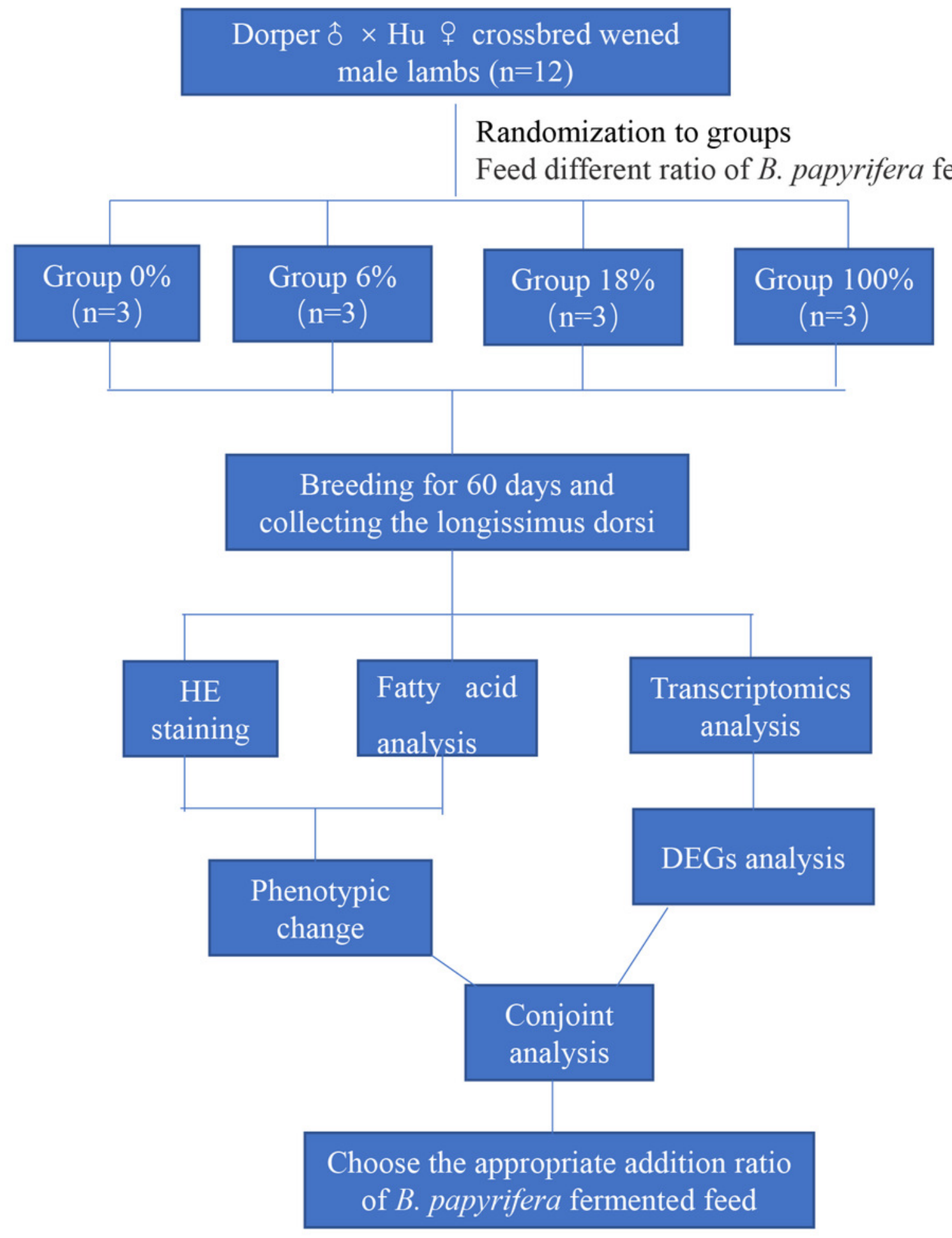




\section{Figure 2}

Figure 2. Morphological characteristics of $H \& E$ between the LD of the sheep with different B. papyrifera fermented feeds.

A-D was the morphology of the longitudinal view of LD under microscope at $40 x$ times magnification, and E-H was the morphology of the transverse view of LD under microscope at $20 \times$ magnification. (1) indicates the epimysium, (2) indicates the endomysium, (3) indicates the muscle fiber, (4) indicates the blood vessel, (5) indicates the nerve, and (6) indicates the cell nucleus. I and J was muscle fiber's diameter and area in different groups.

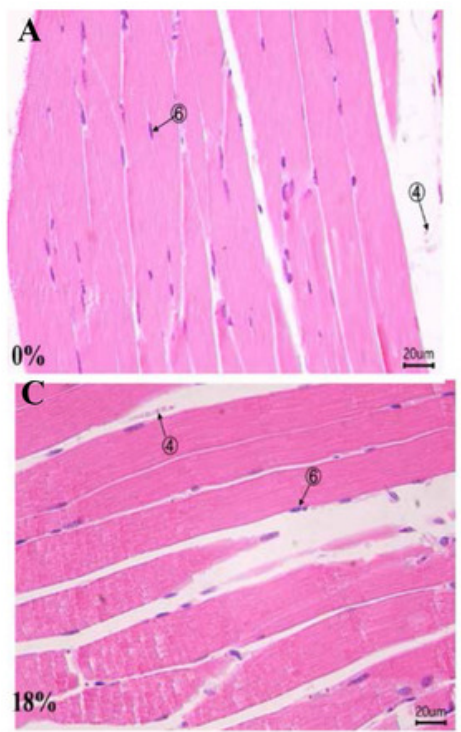

I

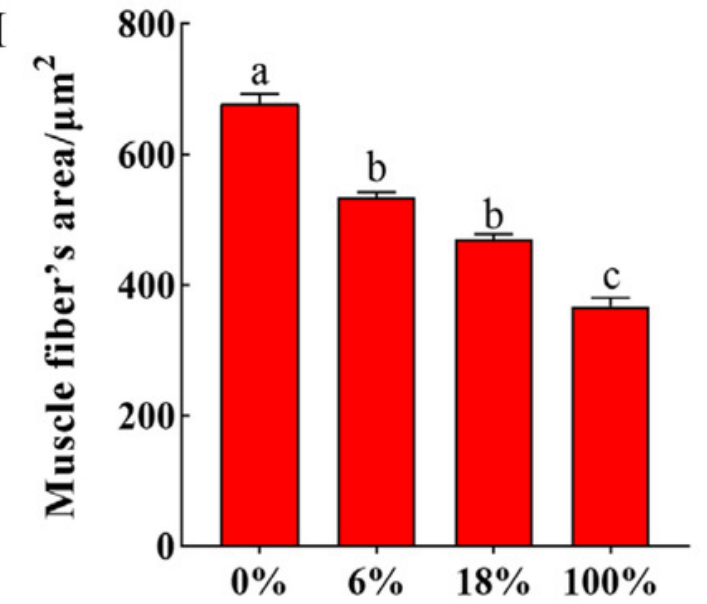

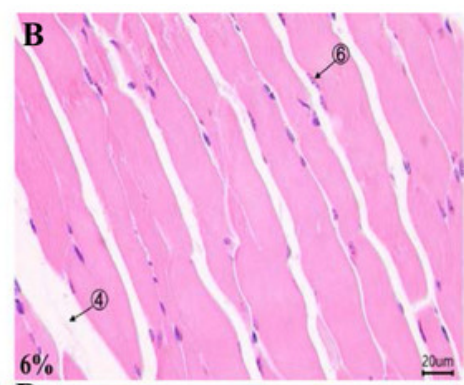
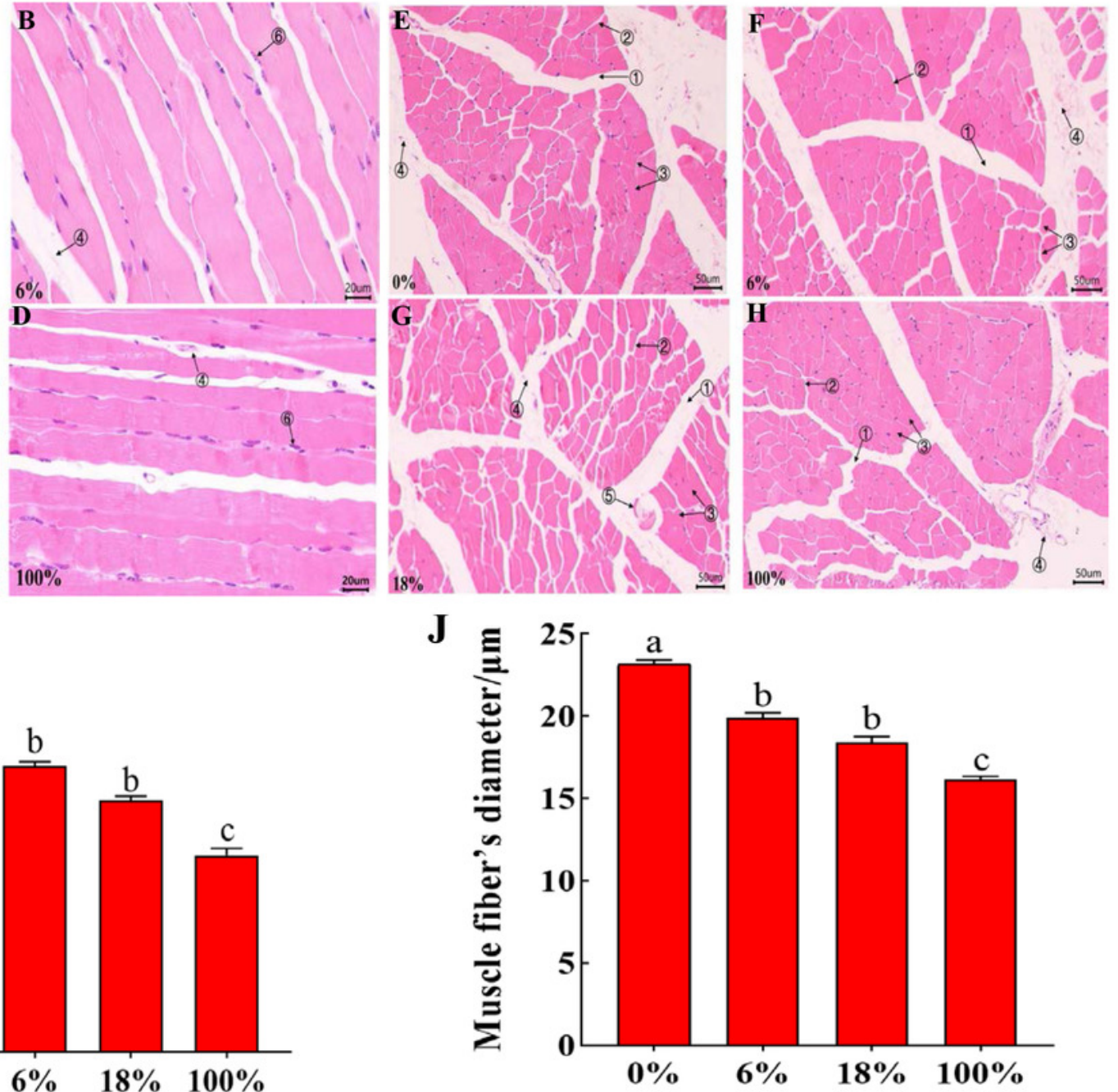
Figure 3

Figure 3. The expression profile of differentially expressed genes (DEGs) of sheep's LD after adding different $\mathrm{B}$. papyrifera fermented feed.

(A) Venn diagrams representing the numbers of DEGs and the overlaps of sets obtained across three comparisons. (B) Column diagram representing the numbers of DEGs in three groups. (C) The heat map representing the expression profile of 50 of the 443 DEGs.

A

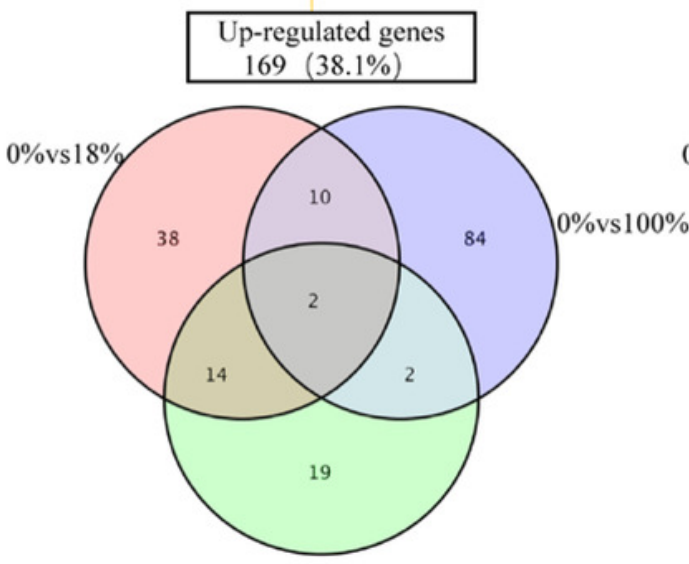

B

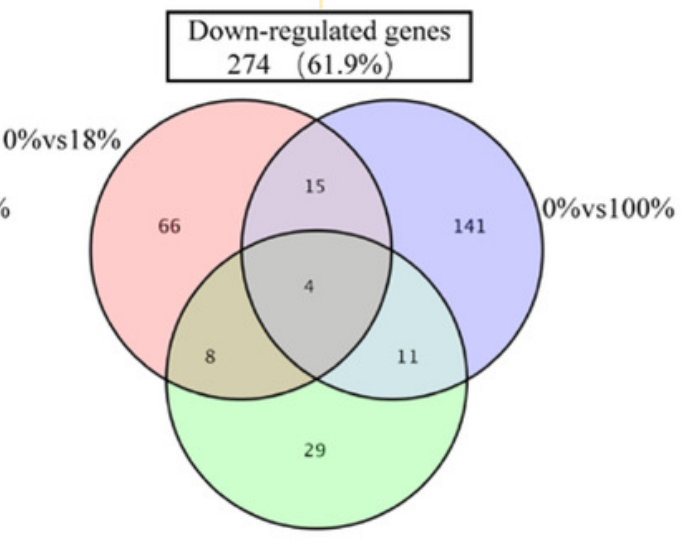

$0 \% \mathrm{vs} 6 \%$

$0 \%$ vs $6 \%$

C
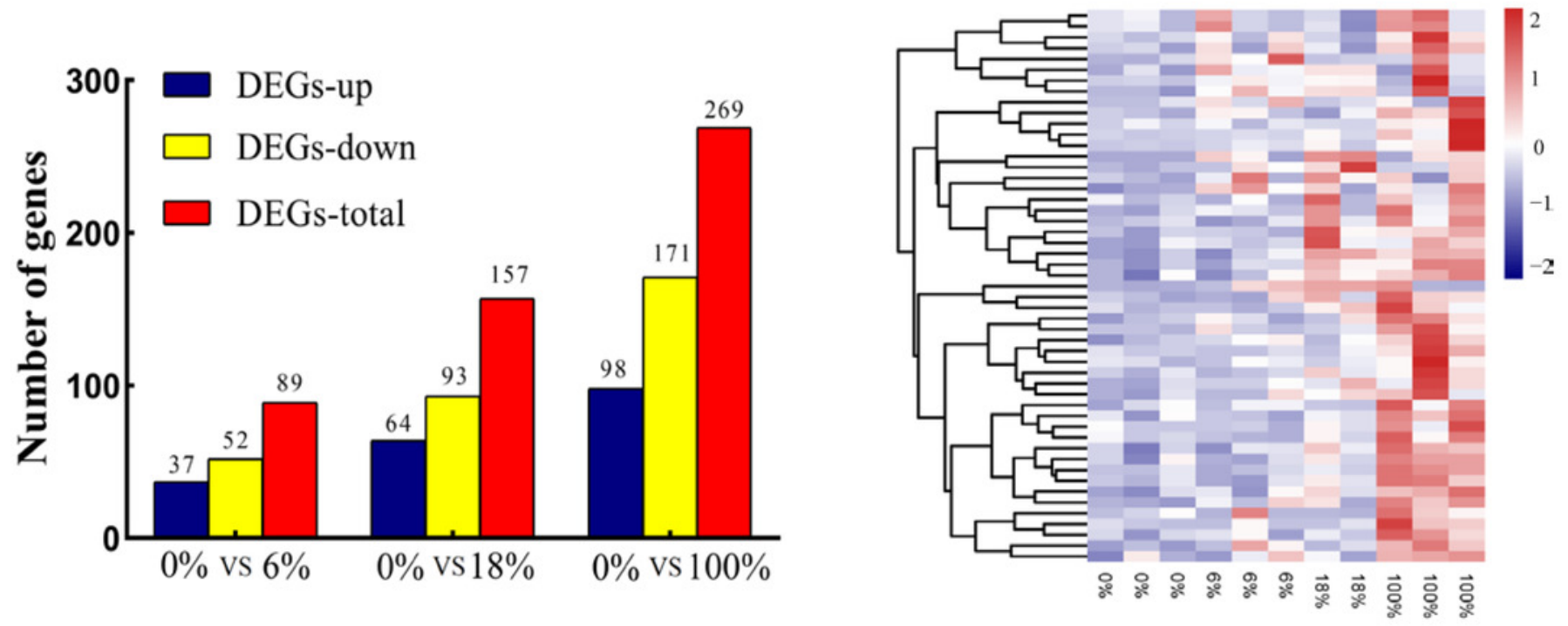


\section{Figure 4}

Figure 4. Co-expression clustering, showing the expression profile of 443 DEGs.

The $X$ axis represents the amount of different Broussonetia papyrifera fermented feed $(0,6$, 18 and 100\%). The $Y$ axis represents the value of the relative expression level (log2 (FPKM + $1)$.

Figure 5

Figure 5. GO functional annotation of the differentially expressed genes (DEGs) of sheep's LD in different groups.

(A) up-regulated DEGs, (B) down-regulated DEGs. 

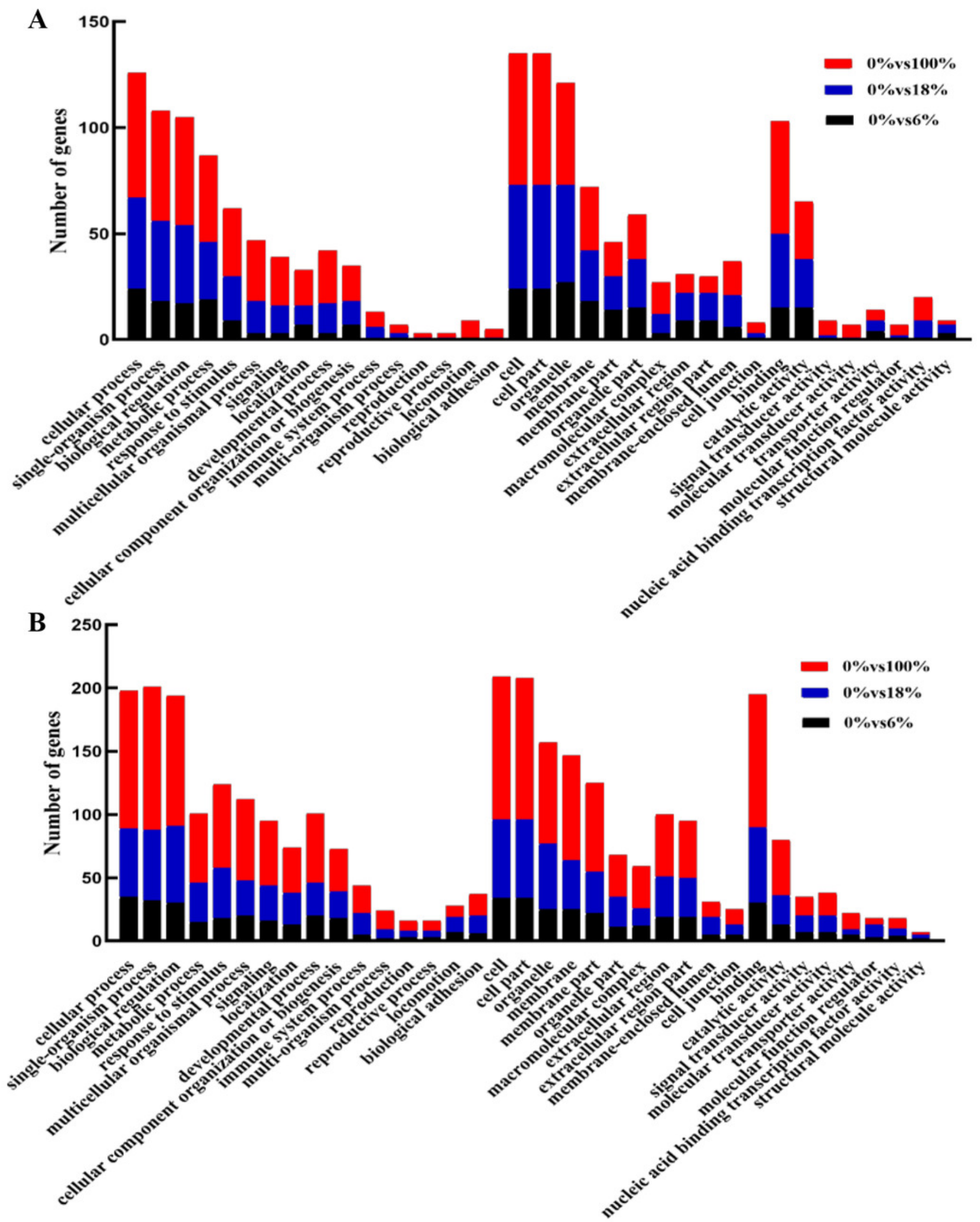
Figure 6

Figure 6. KEGG pathway enrichment of the differentially expressed genes (DEGs) of sheep's dorsal longest muscle in different groups.

(A) up-regulated DEGs, (B) down-regulated DEGs
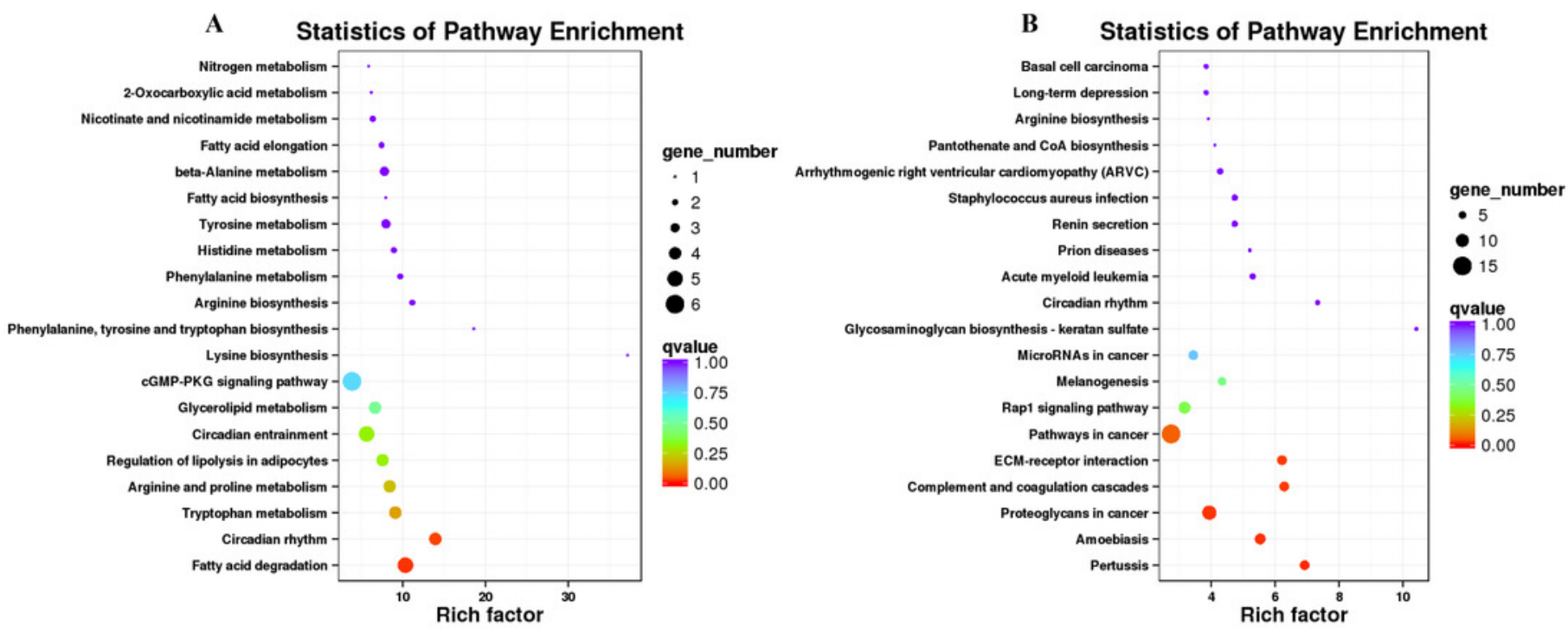


\section{Figure 7}

Figure 7. qRT-PCR analysis of selected DEG genes in the longissimus dorsi of sheep fed with different Broussonetia fermented feed.

Histogram represent the relative expression level defense by qRT-PCR (right y-axis). Broken line indicate the change in transcript level according to the FPKM value of RNA-seq (left yaxis).
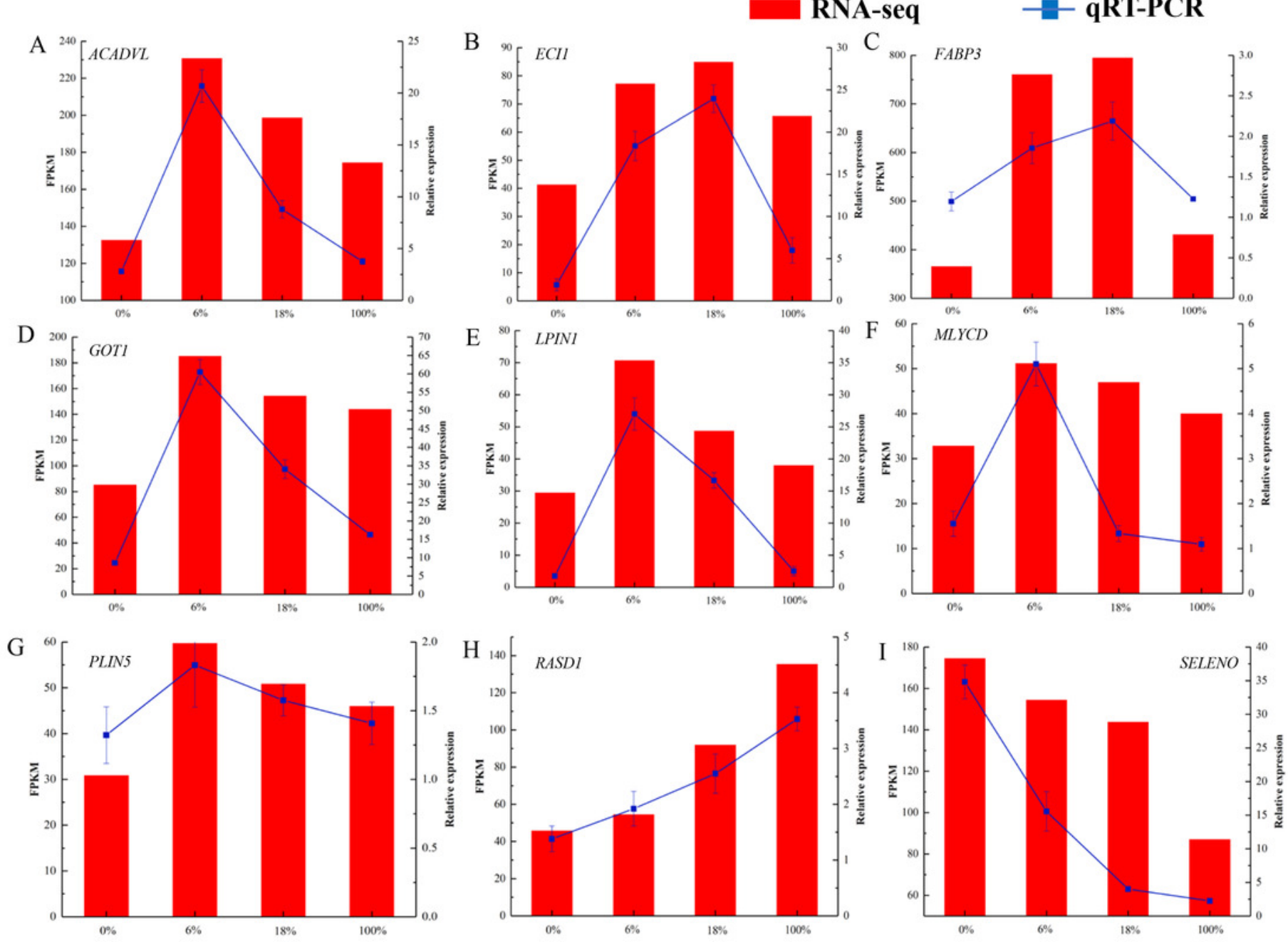
Figure 8

Figure 8. PPI network analysis of identified DEGs associated with fatty acids.Line color indicates the type of interaction evidence.

no

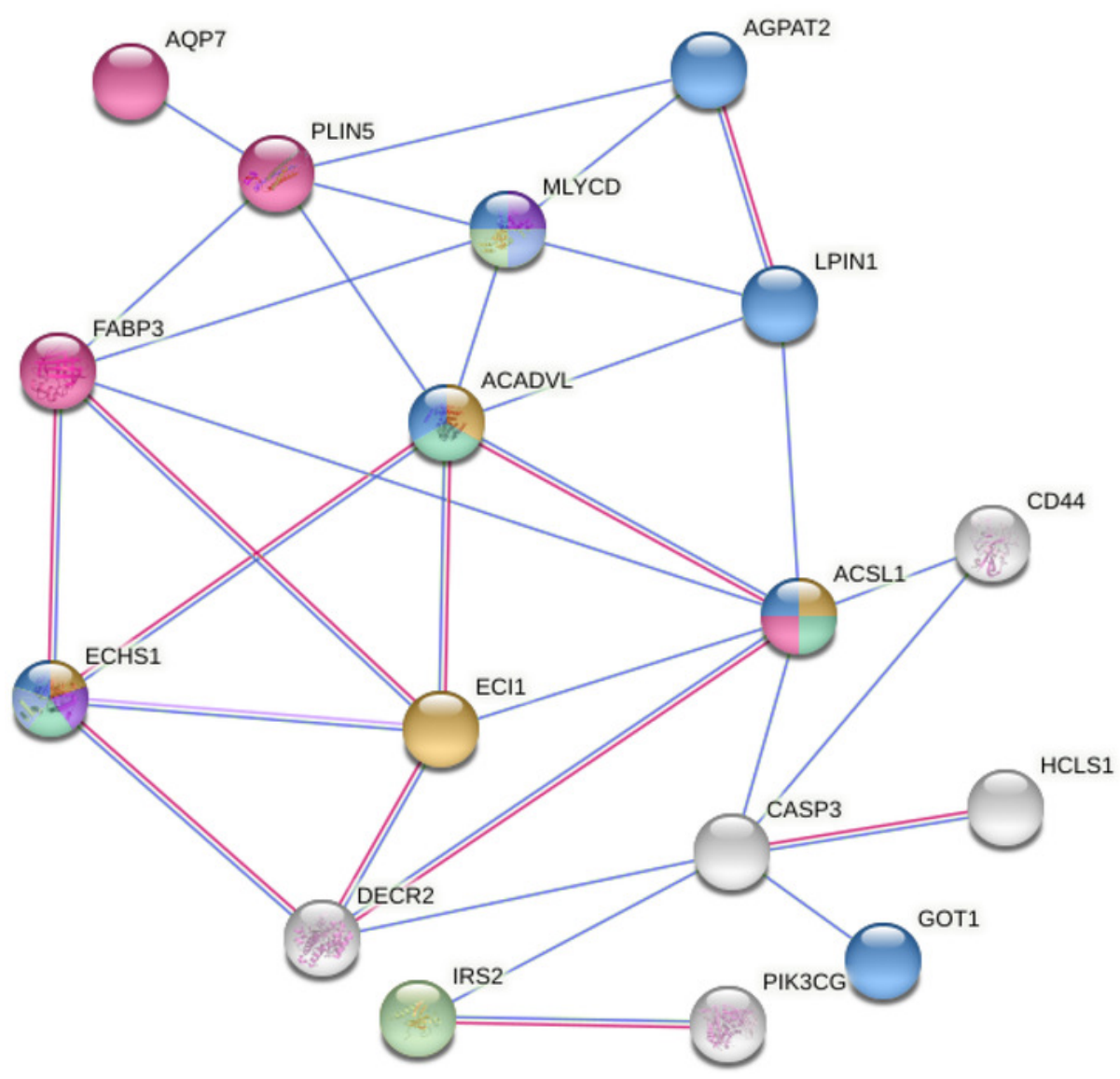

KEGG pathway $($ FDR $<0.05)$

Fatty acid degradation

Propanoate metabolism

Fatty acid metabolism

PPAR signaling pathway

AMPK signaling pathway

Metabolic pathways 


\section{Table $\mathbf{1}$ (on next page)}

Table 1 Composition and nutrient levels of experimental diets (DM basis) \%

The Premix Provided the following per kg of diets: VA 220000 IU, VD3 72000 IU, VE 2000 IU, D-biotin 40.0Mixed group, nicotinic acid amide 2000 Mixed group, Mn (as manganese sulfate) 710 Mixed group, Zn (as zinc sulfate) 2005 Mixed group, Fe (as ferrous sulfate) 830.0 Mixed group, Cu (as copper sulfate) 680.0 Mixed group, Go (as Cobalt sulfate) 12 Mixed group. 
Table 1 Composition and nutrient levels of experimental diets (DM basis) \%

2

3

\begin{tabular}{|c|c|c|c|c|}
\hline Items & $0 \%$ & $6 \%$ & $18 \%$ & $100 \%$ \\
\hline \multicolumn{5}{|l|}{ Ingredients } \\
\hline $\begin{array}{l}\text { B. papyrifera fermented } \\
\text { feed }\end{array}$ & 0.0 & 6.0 & 18.0 & 100 \\
\hline Corn silage & 45.7 & 39.3 & 22.5 & 0.0 \\
\hline Corn & 16.6 & 21.5 & 36.8 & 0.0 \\
\hline Soybean meal & 26.7 & 23.5 & 17.7 & 0.0 \\
\hline Bran & 8.1 & 7.3 & 3.3 & 0.0 \\
\hline Limestone & 1.2 & 0.7 & 0.00 & 0.0 \\
\hline $\mathrm{NaCl}$ & 0.7 & 0.7 & 0.7 & 0.0 \\
\hline Premix 1\% & 1.0 & 1.0 & 1.0 & 1.0 \\
\hline Total & 100.0 & 100.0 & 100.0 & 100.0 \\
\hline \multicolumn{5}{|l|}{ Nutrient levels } \\
\hline $\mathrm{DE}(\mathrm{MJ} / \mathrm{kg})$ & 10.38 & 10.35 & 10.36 & 8.13 \\
\hline $\mathrm{CP}$ & 17.42 & 17.40 & 17.40 & 26.10 \\
\hline $\mathrm{Ca}$ & 20.50 & 19.47 & 15.95 & 15.90 \\
\hline $\mathrm{TP}$ & 11.06 & 10.58 & 8.9 & 13.00 \\
\hline NDF & 0.60 & 0.61 & 0.72 & 3.40 \\
\hline $\mathrm{ADF}$ & 0.34 & 0.33 & 0.30 & 0.20 \\
\hline
\end{tabular}




\section{Table 2 (on next page)}

Table 2 Analysis of saturated fatty acid content and composition in LD muscle ( $\mathrm{g} / 100 \mathrm{~g}$ )

Different lowercase letters in the same industry indicate significant differences $(P<0.05)$. 
1 Table 2 Analysis of saturated fatty acid content and composition in LD muscle (g/100g)

\begin{tabular}{cccccc}
\hline Fatty acid & $\mathbf{0 \%}$ & $\mathbf{6 \%}$ & $\mathbf{1 8 \%}$ & $\mathbf{1 0 0 \%}$ & P-value \\
\hline C4: 0 & $1.96 \pm 0.26$ & $2.79 \pm 0.43$ & $2.49 \pm 0.33$ & $3.33 \pm 0.81$ & 0.279 \\
C10: 0 & $0.19 \pm 0.01$ & $0.16 \pm 0.00$ & $0.14 \pm 0.00$ & $0.16 \pm 0.00$ & 0.912 \\
C12: 0 & $0.12 \pm 0.00 \mathrm{~b}$ & $0.13 \pm 0.00 \mathrm{~b}$ & $0.10 \pm 0.00 \mathrm{~b}$ & $0.25 \pm 0.04 \mathrm{a}$ & 0.037 \\
$\mathrm{C} 13: 0$ & $0.51 \pm 0.056$ & $0.68 \pm 0.07$ & $0.55 \pm 0.05$ & $0.67 \pm 0.12$ & 0.258 \\
$\mathrm{C} 14: 0$ & $2.29 \pm 0.12 \mathrm{~b}$ & $2.27 \pm 0.07 \mathrm{~b}$ & $2.14 \pm 0.07 \mathrm{~b}$ & $2.96 \pm 0.31 \mathrm{a}$ & 0.009 \\
$\mathrm{C} 15: 0$ & $0.39 \pm 0.06 \mathrm{bc}$ & $0.47 \pm 0.05 \mathrm{~b}$ & $0.30 \pm 0.03 \mathrm{c}$ & $0.66 \pm 0.06 \mathrm{a}$ & 0.000 \\
$\mathrm{C} 16: 0$ & $24.21 \pm 0.34$ & $23.82 \pm 0.35$ & $24.18 \pm 0.28$ & $23.63 \pm 0.81$ & 0.693 \\
$\mathrm{C} 17: 0$ & $1.14 \pm 0.09 \mathrm{~b}$ & $1.00 \pm 0.04 \mathrm{bc}$ & $0.89 \pm 0.03 \mathrm{c}$ & $1.36 \pm 0.03 \mathrm{a}$ & 0.000 \\
$\mathrm{C} 18: 0$ & $15.29 \pm 0.43$ & $15.42 \pm 0.73$ & $15.92 \pm 0.56$ & $16.14 \pm 0.64$ & 0.910 \\
$\mathrm{C} 20: 0$ & $0.10 \pm 0.00 \mathrm{~b}$ & $0.11 \pm 0.00 \mathrm{~b}$ & $0.13 \pm 0.00 \mathrm{~b}$ & $0.30 \pm 0.07 \mathrm{a}$ & 0.000 \\
$\mathrm{C} 21: 0$ & $0.46 \pm 0.06 \mathrm{a}$ & $0.34 \pm 0.01 \mathrm{ab}$ & $0.31 \pm 0.01 \mathrm{~b}$ & $0.40 \pm 0.01 \mathrm{~b}$ & 0.030 \\
$\mathrm{C} 22: 0$ & $0.33 \pm 0.03 \mathrm{a}$ & $0.38 \pm 0.04 \mathrm{a}$ & $0.23 \pm 0.03 \mathrm{~b}$ & $0.18 \pm 0.02 \mathrm{~b}$ & 0.000 \\
$\mathrm{C} 23: 0$ & $2.40 \pm 0.30$ & $2.81 \pm 0.47$ & $2.47 \pm 0.27$ & $2.90 \pm 0.58$ & 0.743 \\
\hline
\end{tabular}

2 Different lowercase letters in the same industry indicate significant differences $(P<0.05)$. 


\section{Table 3(on next page)}

Table 3 Analysis of unsaturated fatty acid content and composition in LD muscle $(g / 100 g)$

Different lowercase letters in the same industry indicate significant differences $(P<0.05)$. 
1 Table 3 Analysis of unsaturated fatty acid content and composition in LD muscle (g/100g)

\begin{tabular}{cccccc}
\hline Fatty acid & $\mathbf{0 \%}$ & $\mathbf{6 \%}$ & $\mathbf{1 8 \%}$ & $\mathbf{1 0 0 \%}$ & P-value \\
\hline C14: 1 & $0.24 \pm 0.05$ & $0.31 \pm 0.05$ & $0.30 \pm 0.04$ & $0.34 \pm 0.07$ & 0.600 \\
C15: 1 & $0.27 \pm 0.05 \mathrm{c}$ & $0.32 \pm 0.01 \mathrm{~b}$ & $0.43 \pm 0.02 \mathrm{a}$ & $0.42 \pm 0.04 \mathrm{a}$ & 0.003 \\
$\mathrm{C} 16: 1$ & $1.45 \pm 0.09$ & $1.52 \pm 0.09$ & $1.45 \pm 0.07$ & $1.47 \pm 0.08$ & 0.914 \\
$\mathrm{C} 17: 1$ & $0.50 \pm 0.02 \mathrm{~b}$ & $0.55 \pm 0.01 \mathrm{~b}$ & $0.64 \pm 0.03 \mathrm{~b}$ & $0.97 \pm 0.31 \mathrm{a}$ & 0.042 \\
$\mathrm{C} 18: 1 \mathrm{n} 9 \mathrm{t}$ & $2.97 \pm 0.29 \mathrm{a}$ & $2.51 \pm 0.19 \mathrm{ab}$ & $2.32 \pm 0.04 \mathrm{~b}$ & $2.09 \pm 0.12 \mathrm{~b}$ & 0.012 \\
$\mathrm{C} 18: 1 \mathrm{n} 9 \mathrm{c}$ & $38.30 \pm 0.69 \mathrm{a}$ & $35.49 \pm 0.55 \mathrm{~b}$ & $37.85 \pm 0.27 \mathrm{a}$ & $31.5 \pm 1.16 \mathrm{c}$ & 0.000 \\
$\mathrm{C} 20: 1$ & $0.00 \pm 0.00 \mathrm{~b}$ & $0.00 \pm 0.00 \mathrm{~b}$ & $0.09 \pm 0.00 \mathrm{a}$ & $0.94 \pm 0.00 \mathrm{a}$ & 0.014 \\
$\mathrm{C} 24: 1$ & $0.27 \pm 0.03$ & $0.30 \pm 0.03$ & $0.22 \pm 0.01$ & $0.23 \pm 0.03$ & 0.186 \\
$\mathrm{C} 18: 2 \mathrm{n} 6 \mathrm{t}$ & $0.21 \pm 0.01$ & $0.18 \pm 0.01$ & $0.19 \pm 0.01$ & $0.24 \pm 0.02$ & 0.114 \\
$\mathrm{C} 18: 2 \mathrm{n} 6 \mathrm{c}$ & $5.67 \pm 0.35 \mathrm{c}$ & $6.25 \pm 0.62 \mathrm{~b}$ & $6.28 \pm 0.60 \mathrm{~b}$ & $7.15 \pm 0.50 \mathrm{a}$ & 0.000 \\
$\mathrm{C} 18: 3 \mathrm{n} 6$ & $0.07 \pm 0.01 \mathrm{~b}$ & $0.27 \pm 0.00 \mathrm{a}$ & $0.28 \pm 0.00 \mathrm{a}$ & $0.32 \pm 0.01 \mathrm{a}$ & 0.034 \\
$\mathrm{C} 18: 3 \mathrm{n} 3$ & $0.30 \pm 0.01 \mathrm{~b}$ & $0.39 \pm 0.04 \mathrm{~b}$ & $0.45 \pm 0.00 \mathrm{~b}$ & $2.31 \pm 0.31 \mathrm{a}$ & 0.005 \\
$\mathrm{C} 20: 2$ & $0.2 \pm 0.03 \mathrm{a}$ & $0.00 \pm 0.00 \mathrm{~b}$ & $0.29 \pm 0.02 \mathrm{a}$ & $0.32 \pm 0.00 \mathrm{a}$ & 0.005 \\
C20:3n6 & $0.19 \pm 0.02 \mathrm{a}$ & $0.22 \pm 0.02 \mathrm{a}$ & $0.20 \pm 0.02 \mathrm{a}$ & $0.12 \pm 0.01 \mathrm{~b}$ & 0.000 \\
$\mathrm{C} 22: 6 \mathrm{n} 3$ & $0.18 \pm 0.01 \mathrm{~b}$ & $0.21 \pm 0.02 \mathrm{~b}$ & $0.27 \pm 0.02 \mathrm{~b}$ & $0.64 \pm 0.12 \mathrm{a}$ & 0.000 \\
\hline
\end{tabular}

2 Different lowercase letters in the same industry indicate significant differences $(P<0.05)$.

3 


\section{Table 4 (on next page)}

Table 4 Analysis of total fatty acid content in LD muscle $(\mathrm{g} / 100 \mathrm{~g})$

SFA: saturated fatty acids; UFA: unsaturated fatty acid; MUFA: monounsaturated fatty acids; PUFA: polyunsaturated fatty acids; M / S: monounsaturated fatty acids / saturated fatty acids;

P / S: polyunsaturated fatty acids / saturated fatty acids; n3: n3 polyunsaturated fatty acids; N6: n6 Polyunsaturated fatty acids; N6 / n3: n6 polyunsaturated fatty acid / n3 polyunsaturated fatty acids Different lowercase letters in the same industry indicate significant differences $(P<0.05)$. 
1 Table 4 Analysis of total fatty acid content in LD muscle (g/100g)

\begin{tabular}{cccccc}
\hline Fatty acid & $\mathbf{0 \%}$ & $\mathbf{6 \%}$ & $\mathbf{1 8 \%}$ & $\mathbf{1 0 0 \%}$ & P-value \\
\hline SFA & $49.21 \pm 0.46 \mathrm{~b}$ & $50.17 \pm 0.63 \mathrm{~b}$ & $49.52 \pm 0.77 \mathrm{~b}$ & $52.61 \pm 0.40 \mathrm{a}$ & 0.000 \\
UFA & $50.79 \pm 0.46 \mathrm{a}$ & $49.20 \pm 0.26 \mathrm{~b}$ & $50.44 \pm 0.76 \mathrm{a}$ & $46.79 \pm 0.25 \mathrm{c}$ & 0.001 \\
MUFA & $44.17 \pm 0.60 \mathrm{a}$ & $41.12 \pm 0.52 \mathrm{~b}$ & $42.97 \pm 0.23 \mathrm{~b}$ & $37.09 \pm 1.31 \mathrm{c}$ & 0.000 \\
PUFA & $6.63 \pm 0.35 \mathrm{~b}$ & $7.46 \pm 0.47 \mathrm{ab}$ & $8.09 \pm 0.54 \mathrm{ab}$ & $9.70 \pm 1.32 \mathrm{a}$ & 0.015 \\
M/S & $0.90 \pm 0.04$ & $0.82 \pm 0.03$ & $0.87 \pm 0.02$ & $0.74 \pm 0.05$ & 0.194 \\
P/S & $0.13 \pm 0.01 \mathrm{~b}$ & $0.16 \pm 0.02 \mathrm{~b}$ & $0.15 \pm 0.03 \mathrm{~b}$ & $0.18 \pm 0.05 \mathrm{a}$ & 0.009 \\
$\mathrm{n} 3$ & $0.20 \pm 0.02 \mathrm{~b}$ & $0.32 \pm 0.02 \mathrm{~b}$ & $0.23 \pm 0.02 \mathrm{~b}$ & $0.79 \pm 0.19 \mathrm{a}$ & 0.003 \\
$\mathrm{n} 6$ & $6.08 \pm 0.35$ & $6.64 \pm 0.65$ & $7.58 \pm 0.46$ & $7.99 \pm 1.44$ & 0.511 \\
$\mathrm{n} 6 / \mathrm{n} 3$ & $31.65 \pm 2.75 \mathrm{a}$ & $21.70 \pm 2.85 \mathrm{~b}$ & $31.78 \pm 2.83 \mathrm{a}$ & $12.95 \pm 1.23 \mathrm{~b}$ & 0.000 \\
\hline
\end{tabular}

2 SFA: saturated fatty acids; UFA: unsaturated fatty acid; MUFA: monounsaturated fatty acids; PUFA:

3 polyunsaturated fatty acids; M / S: monounsaturated fatty acids / saturated fatty acids; P / S: polyunsaturated

4 fatty acids / saturated fatty acids; n3: n3 polyunsaturated fatty acids; N6: n6 Polyunsaturated fatty acids; N6 /

5 n3: n6 polyunsaturated fatty acid / n3 polyunsaturated fatty acids

6 Different lowercase letters in the same industry indicate significant differences $(P<0.05)$. 


\section{Table 5 (on next page)}

Table 5. The alignment statistics result with the reference gene for all samples

Clean reads: the number of clean reads, the single-ended meter; Clean bases: the number of clean data; GC content: the percentage of GC-content in clean data; $\geq Q 30$ : Q-score of clean data $\geq 30$; Mapped reads: the number of reads mapped to the reference genome and its percentage in clean reads; Unique mapped reads: the number of reads mapped to the only location of the reference genome and its percentage in clean reads. 
1 Table 5. The alignment statistics result with the reference gene for all samples

\begin{tabular}{|c|c|c|c|c|c|c|}
\hline Samples & Clean reads & Clean bases & $\begin{array}{c}\text { GC } \\
\text { Content }\end{array}$ & $\% \geq \mathbf{Q 3 0}$ & Mapped Reads & $\begin{array}{c}\text { Uniq Mapped } \\
\text { Reads }\end{array}$ \\
\hline $0 \%$ & $24,777,328$ & $7,408,041,508$ & $52.00 \%$ & $93.85 \%$ & $\begin{array}{c}48,003,609 \\
(96.87 \%)\end{array}$ & $\begin{array}{c}41,605,368 \\
(83.96 \%)\end{array}$ \\
\hline $0 \%$ & $25,135,312$ & $7,514,998,722$ & $51.72 \%$ & $93.65 \%$ & $\begin{array}{c}48,766,426 \\
(97.01 \%)\end{array}$ & $\begin{array}{c}41,325,592 \\
(82.21 \%)\end{array}$ \\
\hline $0 \%$ & $20,761,096$ & $6,203,482,124$ & $52.00 \%$ & $93.57 \%$ & $\begin{array}{c}40,190,518 \\
(96.79 \%)\end{array}$ & $\begin{array}{c}35,283,301 \\
(84.97 \%)\end{array}$ \\
\hline $6 \%$ & $27,093,623$ & $8,116,866,124$ & $51.57 \%$ & $94.78 \%$ & $\begin{array}{c}52,862,303 \\
(97.55 \%)\end{array}$ & $\begin{array}{c}45,396,003 \\
(83.78 \%)\end{array}$ \\
\hline $6 \%$ & $26,301,881$ & $7,853,198,780$ & $51.97 \%$ & $95.52 \%$ & $\begin{array}{c}51,254,489 \\
(97.44 \%)\end{array}$ & $\begin{array}{c}43,515,259 \\
(82.72 \%)\end{array}$ \\
\hline $6 \%$ & $26,594,668$ & $7,930,975,080$ & $51.25 \%$ & $95.64 \%$ & $\begin{array}{c}51,935,621 \\
(97.64 \%)\end{array}$ & $\begin{array}{c}43,423,485 \\
(81.64 \%)\end{array}$ \\
\hline $18 \%$ & $20,815,698$ & $6,220,607,222$ & $51.89 \%$ & $94.32 \%$ & $\begin{array}{c}40,451,204 \\
(97.17 \%)\end{array}$ & $\begin{array}{c}33,974,223 \\
(81.61 \%)\end{array}$ \\
\hline $18 \%$ & $21,106,226$ & $6,303,522,828$ & $51.31 \%$ & $93.97 \%$ & $\begin{array}{c}40,921,787 \\
(96.94 \%)\end{array}$ & $\begin{array}{c}33,937,852 \\
(80.40 \%)\end{array}$ \\
\hline $100 \%$ & $20,274,560$ & $6,070,610,678$ & $51.57 \%$ & $95.16 \%$ & $\begin{array}{c}39,563,205 \\
(97.57 \%)\end{array}$ & $\begin{array}{c}33,684,553 \\
(83.07 \%)\end{array}$ \\
\hline $100 \%$ & $25,188,343$ & $7,525,791,384$ & $52.38 \%$ & $95.41 \%$ & $\begin{array}{c}49,093,882 \\
(97.45 \%)\end{array}$ & $\begin{array}{c}43,162,872 \\
(85.68 \%)\end{array}$ \\
\hline $100 \%$ & $24,637,084$ & $7,352,446,008$ & $52.99 \%$ & $94.59 \%$ & $\begin{array}{c}47,927,686 \\
(97.27 \%)\end{array}$ & $\begin{array}{c}42,256,798 \\
(85.76 \%)\end{array}$ \\
\hline
\end{tabular}

2 Note: Clean reads: the number of clean reads, the single-ended meter; Clean bases: the number of clean data;

3 GC content: the percentage of GC-content in clean data; $\geq Q$ 30: Q-score of clean data $\geq 30$; Mapped reads: the 4 number of reads mapped to the reference genome and its percentage in clean reads; Unique mapped reads: the 5 number of reads mapped to the only location of the reference genome and its percentage in clean reads. 